Reviews in Oncology/Hematology

Elsevier Editorial System(tm) for Critical

Manuscript Draft

Manuscript Number: CROH-D-19-00181R1

Title: Gastroenteropancreatic Neuroendocrine Neoplasms and Inflammation: a Complex Cross-Talk with Relevant Clinical Implications

Article Type: Review Article

Section/Category: Solid Tumors

Keywords: Neuroendocrine tumors; inflammation; tumor microenvironment; immune system; cytokines.

Corresponding Author: Professor GIOVANNI VITALE,

Corresponding Author's Institution:

First Author: GIOVANNI VITALE

Order of Authors: GIOVANNI VITALE; Silvia Carra; Francesco Ferraù; Elia Guadagno; Antongiulio Faggiano; Annamaria Colao

Abstract: Neuroendocrine neoplasms (NENs) are a group of tumors originating from the neuroendocrine system. They mainly occur in the digestive system and the respiratory tract. It is well-know a strict interaction between neuroendocrine system and inflammation, which can play an important role in NEN carcinogenesis. Inflammatory mediators, which are produced by the tumor microenvironment, can favor cancer induction and progression, and can promote immune editing. On the other hand, a balanced immune system represents a relevant step in cancer prevention through the elimination of dysplastic and cancer cells. Therefore, an inflammatory response may be both pro- and antitumorigenic. In this review, we provide an overview concerning the complex interplay between inflammation and gastroenteropancreatic NENs, focusing on the tumorigenesis and clinical implications in these tumors 


\section{Cover Letter}

Milan, 20 $0^{\text {th }}$ November 2019

Dear Editor,

please find enclosed our revised manuscript entitled: "Gastroenteropancreatic Neuroendocrine Neoplasms and Inflammation: a Complex Cross-Talk with Relevant Clinical Implications" - Ms. Ref. No.: CROH-D-19-00181, which is submitted for consideration for publication on Critical Reviews in Oncology/Hematology

We have mostly appreciated the comments of reviewers, and we have tried to follow their helpful suggestions in order to ameliorate the manuscript.

Changes are incorporated in the text and highlighted in yellow. Below you can find our point-bypoint responses to the useful issues raised by the referees.

We hope now that this revised version of the manuscript can encounter the publication priority of your prestigious journal.

Thank you again for your kind consideration.

Best Regards,

Giovanni Vitale 


\section{Reviewers' Comments to Author:}

\section{Referee \# 1}

The present review describes neuroendocrine neoplasms (NENs), a group of tumors originating from the neuroendocrine system deriving from digestive system and the respiratory tract and their interaction with inflammatory components of the tumor microenvironment. Moreover, an overview concerning the complex interplay between inflammation and gastroenteropancreatic NENs, focusing on the tumorigenesis and clinical implications in these tumors is provided. The review is well written depicting a new frame for the NENs and describing new pivotal trials on NENs based upon the use of immunological check option inhibitors.

Answer: We thank the reviewer for his/her insightful comment.

1) Please describe more deeply the role of somatostin receptors in the regulation of the immune system. Add maximum 200 words citing the most relevant manuscripts.

Answer: A short paragraph concerning the role of somatostatin receptors in the regulation of the immune system has been included.

2) Please cite and discuss in the text the pivotal clinical study on medullary thyroid cancer based upon the combination of lanreotide and interleukin 2 a t low dosages (J Clin Endocrinol Metab. 2013 Oct;98(10):E1567-74. )

Answer: We thank the reviewer for his/her insightful comment. We have revised the manuscript accordingly

3) Please cite shortly the role of zebrafish in the study of tumor microenvironment

Answer: A short view concerning the role of the zebrafish model in the study of tumor microenvironment has been reported.

4) Please prepare a figure describing the proposed mechanisms

Answer: A new figure has been added (Figure 1).

5) some misreadings in the text should be corrected.

Answer: We carefully revised the text and few typing errors have been corrected. 


\section{Referee \# 2}

A well-written review on an interesting topic. The authors should consider discussing and adding the following 3 references:

- doi: 10.1016/j.critrevonc.2019.02.012. Epub 2019 Mar 2. A rare rarity: Neuroendocrine tumor of the esophagus.

- The tumor immune microenvironment in gastroenteropancreatic neuroendocrine neoplasms. Biochim Biophys Acta Rev Cancer. 2019 Aug 20;1872(2):188311. doi: 10.1016/j.bbcan.2019.188311.

- The prognostic value of the systemic inflammatory response in randomised clinical trials in cancer: A systematic review. Dolan RD, Laird BJA, Horgan PG, McMillan DC.

Answer: We thank the reviewer for this suggestion. Text has been revised accordingly and new references have been included (ref 2, 5 and 126). 


\section{Gastroenteropancreatic Neuroendocrine Neoplasms and Inflammation: a Complex Cross-Talk with Relevant Clinical Implications}

Giovanni Vitale ${ }^{1,2}$, Silvia Carra ${ }^{3}$, Francesco Ferraù ${ }^{4}$, Elia Guadagno ${ }^{5}$, Antongiulio Faggiano ${ }^{6}$, Annamaria $\mathrm{Colao}^{7}$, on behalf of NIKE

${ }^{1}$ Laboratorio Sperimentale di Ricerche di Neuroendocrinologia Geriatrica ed Oncologica, Istituto Auxologico Italiano IRCCS, Milan, Italy.

${ }^{2}$ Department of Clinical Sciences and Community Health (DISCCO), University of Milan, Milan, Italy

${ }^{3}$ Laboratory of Endocrine and Metabolic Research, Istituto Auxologico Italiano IRCCS, Milan, Italy ${ }^{4}$ Department of Human Pathology of Adulthood and Childhood "G. Barresi", University of Messina, Messina, Italy

${ }^{5}$ Department of Advanced Biomedical Sciences, Pathology Section, University of Naples Federico II, Naples, Italy

${ }^{6}$ Department of Experimental Medicine, Sapienza University of Rome, Rome, Italy

${ }^{7}$ Department of Clinical Medicine and Surgery, University of Naples Federico II, Naples, Italy

Corresponding author: Giovanni Vitale; Email: giovanni.vitale@unimi.it

\section{Acknowledgements}

This review is part of the 'Neuroendocrine Tumors Innovation Knowledge and Education' project led by Prof. Annamaria Colao and Prof. Antongiulio Faggiano, which aims at increasing the knowledge on NET.

We would like to acknowledge all the Collaborators of the "NIKE" project: Albertelli M., Altieri B., Ambrosetti E., Bianchi A., Bottiglieri L., Campione S., De Cicco F., Di Dato C., Di Molfetta S., Fanciulli G., Gallo M., Giannetta E., Grillo F., Grossrubatscher E., Guarnotta V., Lo Calzo F., Malandrino P., Martini C., Messina E., Modica R., Muscogiuri G., Pizza G., Razzore P., Rizza L., Rubino M., Ruggeri R., Sciammarella C., Zatelli M.C.

\section{Conflict of interest statement}


A. Colao and A. Faggiano has received consultant fees from Novartis and Ipsen. G. Vitale has received consultant fees from Novartis.

\section{Funding source}

This work was supported by the Italian Ministry of Education, University and Research (MIUR):

PRIN 2017Z3N3YC. 


\title{
Gastroenteropancreatic Neuroendocrine Neoplasms and Inflammation: a Complex Cross-Talk with Relevant Clinical Implications
}

\begin{abstract}
Neuroendocrine neoplasms (NENs) are a group of tumors originating from the neuroendocrine system. They mainly occur in the digestive system and the respiratory tract. It is well-know a strict interaction between neuroendocrine system and inflammation, which can play an important role in NEN carcinogenesis. Inflammatory mediators, which are produced by the tumor microenvironment, can favor cancer induction and progression, and can promote immune editing. On the other hand, a balanced immune system represents a relevant step in cancer prevention through the elimination of dysplastic and cancer cells. Therefore, an inflammatory response may be both pro- and antitumorigenic. In this review, we provide an overview concerning the complex interplay between inflammation and gastroenteropancreatic NENs, focusing on the tumorigenesis and clinical implications in these tumors.
\end{abstract}

Key words: Neuroendocrine tumors, inflammation, tumor microenvironment, immune system, cytokines 


\section{Introduction}

Neuroendocrine neoplasms (NENs) are a group of tumors originating from the neuroendocrine system. NENs develop most commonly in the gastroenteropancreatic (GEP) tract $[1,2]$. Despite the seven-fold increase in NEN incidence in the last four decades, no clear risk factors have been recognized for these tumors. Research over the last decades has underlined the dual role of inflammation in the development and progression of malignancies. Chronic and unbalanced inflammation enhances tumorigenesis. This relationship could be hypothesized also in GEP NEN development, as chronic inflammatory diseases and chronic gastritis are well known predisposing conditions for these tumors. However, under specific inflammatory conditions, immune cells are able to eliminate dysplastic and cancer cells. In this review, we provide an overview concerning the complex interplay between inflammation and GEP NENs, focusing on the tumorigenesis and clinical implications in these tumors.

\section{Role of microenvironment in tumorigenesis and progression of GEP NENs through modulation of inflammation}

The tumor microenvironment (TME) is a dynamic compartment that develops during cancer evolution. TME is not simply constituted by neoplastic cells, but it includes blood and lymphatic vascular networks, extracellular matrix, cancer-associated fibroblasts (CAFs), adipose cells, neuroendocrine cells, immune-inflammatory cells and different molecular players, such as proinflammatory and oncogenic mediators [3]. The interplay between all these elements, in particular the inflammatory microenvironment, is crucial to shape the fate and the evolution of several tumors (figure 1). Although underestimated until now, TME has a relevant role in tumorigenesis, progression and response to the therapy in GEP NENs [4, 5].

\subsection{Vasculature}

Blood and lymphatic vessels deliver nutrients and oxygen, necessary for cancer survival, and are relevant for tumor progression and the development of immune cell infiltration. The hypoxic tumor microenvironment prompts the release of proangiogenic factors, like vascular endothelial growth factor (VEGF), fibroblast growth factor (FGF), platelet-derived growth factor (PDGF) and transforming growth factor $\beta$ (TGF- $\beta$ ), promoting the rapid and aberrant vasculature formation within the tumor [6]. NENs are highly vascularized. The development of new blood vessels involves different proangiogenic factors. The best known and characterized is surely VEGF and its receptors (VEGFRs). VEGF overexpression is generally associated to an increased microvascular 
density, leading to tumor progression. GEP NENs are characterized by a marked expression of VEGF/VEGFRs [7, 8], but the relationship between VEGF, tumor vascularization and prognosis is not straightforward. In gastrointestinal NENs this correlation is unclear, only in pancreatic NENs it has been reported that VEGF expression is higher in benign and low-grade tumors. Therefore, this condition results to be associated to a good prognosis and prolonged survival [9, 10]. A comprehensive explanation for this paradox could be that in pancreatic NENs the vascular density is more likely a marker of differentiation than a marker of aggressiveness. FGF, PDGF and TGF- $\beta$ are also strongly expressed in GEP-NENs [4].

In order to study in vivo the tumor-induced angiogenesis, we have developed an innovative model through the xenograft of human NEN cells into $T g(f l i l a: E G F P)^{y 1}$ [11] zebrafish embryos. This transgenic line, expressing the enhanced green fluorescent protein (EGFP) in the endothelial cells of the entire vascular tree, offers the possibility to estimate the proangiogenic potential of injected tumor cells and to analyze the contribution of the TME to the tumor progression in a living selective microenvironment [12-14].

\subsection{Reactive stromal cells}

Extracellular matrix is structurally constituted by interstitial matrix, which mainly includes stromal cells, and by basement membrane. Extracellular matrix contains soluble molecules, such as chemokines, matrix metalloproteinases, protease inhibitors and growth factors. An abnormal extracellular matrix favors tumor progression, promoting cellular transformation and metastasis [15]. Among different factors involved in extracellular matrix remodeling, proteoglycans play different roles in cancer. In GEP NENs the expression of syndecan 2 and glypican 1 proteoglycans has been reported to be high in well-differentiated tumors. Their levels correlated positively with patient survival [16]. In a recent paper, the prometastatic enzyme heparanase, a glucuronidase, resulted to be overexpressed in well- but not in poorly differentiated NENs [17].

CAFs, a population of activated fibroblasts (also known as myofibroblasts), represent the major non-cancer cells within the tumor stroma. They share properties with fibroblast stimulated by inflammation or wound healing. Indeed, they can secrete a variety of mesenchyme-specific proteins [18], chemokines (CXCL-8 and CXCL-12), cytokines (interleukin-6) and growth factors, including VEGF, TGF- $\beta$, FGF, hepatocyte growth factor and epidermal growth factor (EGF). These factors are involved in paracrine signaling or activate CAFs in autocrine loops. The crosstalk between CAFs and cancer cells is responsible for the promotion and maintaining of the activated phenotype of fibroblasts and, in turn, the production of soluble factors by CAFs fosters the cancer growth and progression, promoting the remodeling of extracellular matrix, cell proliferation and angiogenesis 
[19]. Activated fibroblasts are recruited to the tumor site miming excessive fibrosis, as a consequence of inflammation and aging [20]. It has been observed that NENs are often associated with local or distant fibrosis and that the crosstalk between NEN cells and fibroblasts has a pivotal role in fibrogenesis [21]. The most common examples of fibrosis are mesenteric fibrosis, associated with small bowel NENs in up to 50\% of cases [22], and carcinoid heart disease, characterized by development of fibrotic endocardial plaques, that affects up to $40 \%$ of patients with carcinoid syndrome [23, 24]. Several factors take part in NEN-related fibrogenesis, such as serotonin, connective tissue growth factor, PDGF, insulin-like growth factors (IGFs), FGF and VEGF [21]. A strict interaction between NEN cells and fibroblasts, with a mutual induction of cell proliferation, is relevant for these events [4].

The TME exerts a significant role in every step of tumorigenesis and progression through reciprocal interactions and modulation of chronic inflammation [25]. It is well-known the dual role of immune infiltration in tumors [26]. An imbalance of the immune system may cause chronic inflammation with a pro-oncogenic environment, on the contrary a well-regulated adaptive immune response is considered anti-tumorigenic [27]. Immune surveillance can eliminate some pre-malignant lesions [28], but over time, tumor cells can undergo a process called immune editing [29], becoming resistant to the first line of defense and able to manipulate immune cells through secretion of chemokine and cytokines [26]. Therefore, an inflammatory response may be either pro- or antitumorigenic, depending on the overall balance of inflammatory mediators and on the type of immune cells infiltrating the tumor. These aspects have been also reported in GEP-NENs, where chronic inflammation is a relevant hallmark [1].

Tumor-infiltrating immune cells include $\mathrm{T}$ and $\mathrm{B}$ lymphocytes, natural killer (NK) cells, macrophages, dendritic cells (DC) and neutrophils $[30,31]$. In a contest of chronic inflammation, leukocytes provide directly and indirectly several factors that can promote proliferation of cancer and stromal cells [32], stimulate angiogenesis, facilitate cancer cell dissemination and tumor immune evasion [33].

Tumor-infiltrating lymphocytes contain various proportions of T helper cells (CD4+) and cytotoxic $\mathrm{T}$ cells (CD8+). Their presence is associated with a better prognosis in a wide range of solid tumors $[25,30,34]$. In NENs, particularly in carcinoids of lung and midgut, tumor-infiltrating lymphocytes (CD4+, CD8+ and CD20+) are often found and its occurrence correlates inversely with the presence of metastases [35]. Also pancreatic NENs commonly showed an intratumoral infiltration with CD4+, CD8+ and CD3+ T cells [36]. A recent paper characterized T-cell subpopulations in both intra- and extra-tumoral compartments in small intestine and pancreatic NENs through a panel of Tcell markers, comprising CD3 (general T-cell marker), CD45RO (T memory), CD8 (cytotoxic T 
cell), and FOXP3 (T regulatory cell). T-cells (CD3+, CD45RO+ and CD8+) were observed in both small intestine and pancreatic NENs, with a more relevant infiltration in pancreatic NENs, particularly in the extratumoral compartment. Levels of FOXP3 T regulatory cell infiltration were low in both tumors [37]. However, the expression of regulatory $\mathrm{T}$ cells appears to be not marginal in NENs, particularly in aggressive forms. These cells can stimulate metastasis formation and mediate the suppression of the immune system [38-40]. In another series of NENs, pancreatic intratumoral regulatory $\mathrm{T}$ cell infiltration was present in 55\% of intermediate/high-grade tumors, whereas only in $16 \%$ of low-grade NENs [39]. Patients with midgut carcinoid showed higher levels of circulating regulatory $\mathrm{T}$ cells compared to healthy donors, particularly in patients with a high tumor burden [40].

Macrophages represent a remarkable portion in tumor mass. These cells display a substantial grade of plasticity, with different state of activation in response to a variety of external stimuli. Indeed, macrophages can be polarized into type I (M1) and type II (M2) [41]. M1 macrophages exert an anti-tumor effect, through the production of several pro-inflammatory cytokines, chemokines, and effector molecules, such as interleukin-1 (IL-1), IL-12, IL-23, TNF- $\alpha$, CXCL10, iNOS and MHCI/II. In contrast, M2 macrophages promote tumor proliferation and progression, tumor angiogenesis, metastasis formation and immune suppression, through the expression of a wide spectrum of anti-inflammatory molecules, such as IL-10, TGF- $\beta$ and arginase-1 [41, 42]. M2 macrophages can also switch T-lymphocytes to regulatory $\mathrm{T}$ cells, allowing the suppression of tumor immunity [43]. Numerous studies have demonstrated in most human cancers that a high presence of infiltrated macrophages is linked with poor prognosis [26, 44]. In pancreatic NENs, tumor-associated macrophages infiltration correlates with proliferative activity, tumor grade, presence of liver metastases, angiogenesis and recurrence after surgery [45-47]. In addition, low tumor-associated macrophages, low peritumoral CD4+ cell and high intratumoral CD8+ T cell infiltration was associated with prolonged disease-free and/or disease-specific survival in pancreatic NENs [48].

DCs are key mediators of the adaptive and innate immune responses, therefore, these cells play a pivotal role in shaping the immune response. DCs are designed to present antigens and provide different signals, such as co-stimulatory molecules and cytokines, essential for $\mathrm{T}$ cell activation, to interact with other immune cells, including NK and B cells [49]. Tumor-infiltrating DCs are present in different types of solid tumors and can be associated with both a better and poor prognosis [50]. Besides, phenotype and amount of DCs are dynamic over time and may considerably influence tumor progression [49]. Although a complete characterization of DCs has never been reported in GEP NENs, Schott et al. described that vaccination with tumor lysate-pulsed DCs induced a clear 
antitumor effect in a patient with pancreatic neuroendocrine carcinoma [51]. Interestingly, Papewalis and colleagues identified a population of DCs with NK cell properties, expressing the CD56 NK marker [52]. Afterwards, it has been reported higher numbers of circulating CD14+/CD56+ monocytes in 4 patients with gastrointestinal neuroendocrine cancer compared to healthy controls [53].

NK cells are a subset of innate lymphoid cells and represent about 5-15\% of the circulating blood mononuclear cell population. These cells are involved in the first line of defense against infection and cancer [54, 55]. It has been reported that NK cell activity, expressed as percentage of cytotoxicity in patients with gastrointestinal NENs, is affected by the type of gastrointestinal hormones produced and by the course of the disease with an impairment during tumor progression [56]. In addition, serotonin, the hormone most frequently related to carcinoid syndrome in NENs, stimulates migration of NK cell [57] and protects these cells against oxidatively induced functional inhibition and apoptosis [58].

\subsection{Inflammatory mediators}

The interplay between immune cell components and tumor cells is well orchestrated and several molecular mediators and pathways take part in inflammation-mediated cancer and immune modulation. Common inflammatory mediators are cytokines, chemokines, nuclear factor kappa B (NFk-B), STAT3, cyclooxygenase-2 and reactive oxygen and nitrogen species. An inflammatory stimulus causes the recruitment and activation of different immune cells (macrophages, DCs and neutrophils), which release reactive oxygen and nitrogen species. The over-production of these oxidative agents causes genomic instability, the increase of angiogenesis and transcriptional activation of proto-oncogenes, concurring to inflammation-induced carcinogenesis and tumor metastatic potential [59].

Chronic inflammation plays a critical role in the occurrence of GEP NENs through the network of different cytokines and growth factors, which modulate tumor cell growth [60], such as TNF- $\alpha$, IL2, IL-6, IL-8, IL-1 $\beta$ [61-65]. Noteworthy, cytokine genes are highly polymorphic. Single nucleotide polymorphisms affect cytokine expression and function regulation. $I L-2-330 G / G$ genotype was associated to higher IL-2 serum levels and an higher risk to develop GEP NENs compared to healthy volunteers. Interestingly, highest IL-2 serum levels were observed in patients with functional NENs [61]. Similar associations have been observed between $I L-6-174 G / G$, $T N F-\alpha$ $1031 C$ and $I L-1 \beta-511 C / T$ genotypes, high circulating levels of corresponding cytokines and an increased risk to develop GEP NENs [62, 66, 67]. GEP NENs are characterized by an abundant production and secretion of growth factors, in particular VEGF, EGF, PDGF, IGF, FGF and TGF- $\beta$, 
which, in combination with high level of cytokines, connect chronic inflammation to gastrointestinal carcinogenesis [68-71].

The pro-inflammatory mediators, produced during chronic inflammation, activate several signaling cascades, such as NFk-B and STAT3 pathways, that are central in the development and maintaining of the TME. NFk-B is a transcription factor that, following an inflammatory stimulus, translocates to the nucleus, where it activates transcription of target genes encoding pro-inflammatory cytokines, chemokines, NOS2 and cyclooxygenase-2. Moreover, NFk-B activation stimulates angiogenesis by VEGF secretion and makes tumor cells more resistant to necrosis and apoptosis. NFk-B is linked to different cellular signaling pathways. Over the last years, several reports have described NotchNFk-B pathway crosstalk [72]. In NENs it has been demonstrated that non-canonical Notch signaling impacts on tumorigenesis by the involvement of different signaling pathways, among them NFk-B [72, 73].

The signal transducer and activator of transcription, STAT3, has a relevant role in inducing and maintaining a pro-carcinogenic inflammatory TME. Its persistent activation in cancer cells promotes cell proliferation, tumor invasion and angiogenesis. Like NFk-B, STAT3 is activated by different factors and it can stimulate the transcription of several pro-inflammatory cytokines, controlling inflammation and immune evasion. In GEP NENs STAT3 has been reported to be upregulated and nuclear STAT3 expression correlated with metastatic status [74].

Other players taking part in this complex scenario, are cyclooxygenases. These are enzymes necessary to the production of prostaglandins from fatty acids. Prostaglandins are key mediators in inflammation, and in tumors can affect cell proliferation, DNA mutation rates, angiogenesis and promote metastasis formation [75]. Cyclooxygenase-2 expression has been detected in the vast majority of GEP NENs, both in functioning and non-functioning tumors [76], and its expression has been associated with a poor prognosis and more aggressive pathologic variables [77-79].

Therefore, chronic inflammation promotes tumor, causing genomic instability, increasing angiogenesis, altering the genetic/epigenetic state and increasing cell proliferation. Several studies have shown that GEP NENs are closely associated with inflammatory conditions.

\section{NEN and inflammatory GEP diseases}

The gastrointestinal tract contains the highest concentration of bacteria anywhere within the human body. This organ is constantly exposed to materials originating from the external environment. The balance of the gastrointestinal microbial community is critical not only for this organ but also for 
maintenance of host health. Indeed, failure of gut homeostasis is an important factor in the pathogenesis and progression of systemic inflammation, which has a relevant role in the process of aging and several age-related disease [80, 81].

Throughout the whole gastroenteric tract and pancreas at least 19 types of neuroendocrine cells have been observed. As previously reported, these cells are not exempt from the detrimental effects of long-standing inflammation. Indeed, neuroendocrine cells can be overstimulated by chronic inflammation, leading to hyperplasia and sometimes to dysplasia, that may evolve to neoplastic transformation. This consequential relationship has been demonstrated in some districts of the GEP tract.

\subsection{Gastric NEN}

Gastric NENs are tumors originating from enterochromaffin-like (ECL) cells which are mainly localised in the gastric fundus and corpus. The main role of ECL-cells is the secretion of histamine, that stimulates acid secretion by parietal cells. Clinically, gastric NENs are categorized into types I, II, and III. Type I lesions correspond to the majority of gastric NENs and they are associated with chronic atrophic gastritis, either autoimmune-driven or as a consequence of Helicobacter pylori infection. In chronic atrophic gastritis, the destruction of the gastric parietal cells reduces the production of hydrochloric acid and intrinsic factor, promoting hypergastrinemia and pernicious anemia, respectively. The gastrin excess stimulates ECL cells proliferation and favors the development of type I gastric NEN $[82,83]$.

A population-based case-control study, comparing 1,138,390 cancer cases with 100,000 matched individuals without cancer, showed that subjects with chronic atrophic gastritis associated with pernicious anemia have a significantly increased risk of type I gastric NENs (odds ratio, 11.43; 95\% CI 8.90-14.69) [84]. This tumor arises in patients with chronic atrophic gastritis in a percentage variable from 1 to $11 \%$ [85-88].

Helicobacter pylori is a gram-negative bacterium whose outer membranes are composed by lipopolysaccharides. Experiments made on rat ECL cell preparation showed that Helicobacter pylori lipopolysaccharides stimulate histamine release, that was independent by the gastrin action, and potentiate gastrin-driven DNA synthesis in ECL cells [89].

Other alterations in the gastric microbiota could be also involved in this detrimental process. In fact, hypochlorhydria is able to modify the composition of the gastric microbiota by providing a different environment for colonization. This event could potentially increase the risk of developing a gastric malignancy. A recent study comparing the human gastric microbiota in different conditions, showed that autoimmune atrophic gastritis resulted in greater bacterial abundance and diversity compared to 
normal stomach and patients with Helicobacter pylori-induced atrophic gastritis. In both patients with atrophic gastritis due to autoimmune etiology or Helicobacter pylori, an over-activation of several pathways has been observed compared to controls. Interestingly, gastric-atrophy resulted to be associated with a modulation in the citric acid cycle, a biochemical pathway with a relevant role in gastric carcinogenesis [90].

Therefore, autoimmune stimuli or Helicobacter pylori infection trigger an inflammatory response that determines parietal cell loss [91]. ECL cells are spared by this cellular destruction and induced to proliferate [89]. Indeed, in the setting of type A chronic atrophic corpus-fundus restricted gastritis, both hyperplastic and dysplastic lesions of ECL cells may be observed (figure 2), each bearing increased risk of tumor development [88]. It was shown that a gastric mucosa with severe hyperplasia (at least 6 intraglandular ECL cell chains of at least 5 cells each per mm of mucosa or at least 9 linear plus micronodular changes) and dysplasia (enlarged, fused or stroma dissected micronodules or microinfiltrative lesions) needs to be adequately followed by endoscopy and biopsies because of the increased neoplastic risk of these lesions [88].

\subsection{Pancreatic NEN}

Chronic pancreatitis represents an independent significant risk factor for pancreatic cancer [92, 93]. The strength of the relationship between these two diseases has been widely reported. In a multicenter cohort study of 2015 cases [92] of pancreatitis, 56 cases of pancreatic cancer were registered during a mean follow-up of 7.4 years. Among these, 29 cases were diagnosed 2 years after the diagnosis of pancreatitis. This number was higher than the expected for age, sex and the center. A case-control study [93] analyzed how frequent was the occurrence of pancreatitis in 2639 patients with pancreatic cancer, compared to 7774 control subjects. The evidence was that pancreatitis was present in around $6 \%$ of patients with cancer and it represents a strong risk factor for development of pancreatic tumors. Although in most of these studies the tumor histotype was not specified, this association appears to be relevant for pancreatic adenocarcinoma.

On the other hand, it is less clear the potential association between NEN and pancreatitis. In this setting, even hyperplastic and dysplastic lesions of endocrine cells consequent to inflammation, have never been clearly described. Rather, what is known is that, in the late phase of chronic pancreatitis, an apparent prominence of the endocrine cells is observed, probably due to the preferential loss of acinar tissue. This "pseudohypertrophy" may be difficult to distinguish from neuroendocrine microadenoma (figure 3). Therefore, data related to the incidence of cancer in this setting may be influenced by the potential of incorrect diagnosis of NEN. 
A case-control study including 162 sporadic pancreatic NENs and 648 controls showed that history of chronic pancreatitis $(\mathrm{OR}=8.6 ; 95 \% \mathrm{CI}, 1.4-51)$ and diabetes $(\mathrm{OR}=40.1 ; 95 \% \mathrm{CI}, 4.8-328.9)$ resulted to be independent risk factors for the development of this tumor [94]. Although the association between pancreatic NENs and chronic pancreatitis has been not confirmed in other studies, a recent meta-analysis showed that history of diabetes mellitus was associated with an increased risk of sporadic pancreatic NENs (pooled adjusted odds ratio 2.74, 95\% CI: 1.63-4.62) [95]. It is still unclear whether diabetes is a real risk factor or a secondary effect due to the pancreatic tumor. Furthermore, it is possible that chronic inflammation and oxidative stress may contribute to the pathogenesis of both diabetes and pancreatic NENs through the induction of DNA mutation [96]. A recent study showed that in genetically engineered transgenic mice, chronic inflammation in the absence of TP53 developed in all animals several subtypes of pancreatic cancer, including NENs [97].

\subsection{Small bowel and appendix NEN}

Several chronic inflammatory bowel conditions represent a potential risk factor predisposing to the development of small bowel NENs [98].

In celiac disease (CD), an immune-mediated disorder involving the small bowel, serotoninproducing neuroendocrine cells are increased [99]. Well-oriented bioptic samples taken from 17 patients affected by refractory $\mathrm{CD}$, were compared with 84 non-healthy and 16 healthy control subjects. In this study the number of neuroendocrine cells was absolutely more represented in refractory $\mathrm{CD}$. A higher expression was also observed in case of $\mathrm{CD}$ before gluten-free diet that restored to normality after [99]. This finding was indicative of a possible etiologic role of the immune system in the proliferative activity of these cells [100]. In addition, significantly higher serotonin levels have been described in patients with CD compared to healthy subjects [101]. In a large population-based cohort study, the standardized incidence ratio for small-intestinal cancer (adenocarcinomas, stromal tumors and NENs) was more than fourfold in patients with CD. However, the association between CD and NENs is doubtful. Indeed, in this study there are no data

on the number of patients with NENs [102]. Despite the hyperplasia of entero-chromaffin cells has been demonstrated in $\mathrm{CD}$, only few case reports have been published describing $\mathrm{CD}$ subjects with small bowel NENs [103-107].

Population-based studies [108, 109] have shown that the incidence of NENs is significantly increased in inflammatory bowel diseases (IBD) involving the small bowel. Among a cohort of 20.917 patients affected by Crohn's disease in the time frame between 1978 and 2010, 23 small bowel adenocarcinoma and 9 NENs were observed, resulting, respectively in a 14-fold and 7-fold 
increased neoplastic risk, as compared to the general population. In both histotypes the severity of the surrounding inflammatory disease was moderate to severe and its distribution was extensive. Furthermore, while almost all adenocarcinomas arose in mucosal areas affected by Crohn's disease, $78 \%$ of NENs developed far from them. This suggests that the development of NENs may be secondary to the effects of pro-inflammatory cytokines, rather than a local inflammatory effect from adjacent Crohn's disease. In the same study 42.872 cases of ulcerative colitis were also analyzed and no significantly increased risk of cancer was found among those patients [108].

The appendix is the third more frequent site of gastrointestinal-NENs. Appendiceal NENs are often diagnosed incidentally on histopathological examination of appendectomy specimens. In about two thirds of cases, they are found at the tip of the organ and are not the direct cause of the appendicitis [110]. In case of acute appendicitis, the number of enterochromaffin cells, that populate the crypt epithelium, and of subepithelial neuroendocrine cells is depleted [111]. Although no clear data are available concerning a potential association between chronic appendiceal inflammation and risk of NEN, the inflammation caused by other disease, such as Crohn's disease, represents a favorable situation for the development of the appendiceal NEN. Indeed, it seems to occur more frequently in the samples from inflamed surrounding than that reported in autopsy studies [112].

A recent meta-analysis of observational studies provides additional evidence for a link between inflammation and intestinal NENs. This study reported that aspirin use was associated with a significant decrease in the risk of several tumors, including small intestinal NENs $(R R=0.17,95 \%$ CI: 0.05-0.58) [113].

\subsection{Colonic and rectal NEN}

During inflammatory diseases affecting the colonic and rectal tube, as IBD, post-dysenteric colitis, Campylobacter enteritis and irritable bowel syndrome, an increase in number of neuroendocrine cells (figure 4) can be observed [114]. In all these cases, there is a disruption of the intestinal epithelial barrier that dysregulates innate and immune responses toward the enteric microbiota. This favors the release of several cytokines, that finally affect the commitment of multipotentialsecretory precursor cells and promote the differentiation of enteroendocrine precursor cells [115]. This phenomenon was deepened with in vitro and in vivo models of intestinal inflammation [114], where it was shown that PI3K/Akt signaling and autophagy are implicated in the increase of colonic intestinal epithelial cells expressing chromogranin. Indeed, the concomitant treatment of interferon$\gamma$ plus TNF- $\alpha$ increased the number of chromogranin A-positive cells in the distal colon of colitic mice and this determined an increase of pAkt (Ser473) and pAkt(Thr308), an augmented 


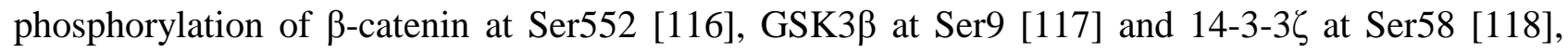
three well-known targets of Akt, and enhanced PTEN phosphorylation. p-PTEN is the inactive form, that causes PI3K/Akt signaling activation in chromogranin A-positive cells. The reason why cytosolic chromogranin A increases in case of inflammation is not clear. It was supposed that entero-endocrine cells, with their capacity of antigen internalization, could represent a relevant sensor for the mucosa during inflammation. Similarly, in humans neuroendocrine differentiation is relatively common and represents an early event in the ulcerative-colitis-associated carcinogenesis, where chromogranin A and p53 are up-regulated [119].

Discordant opinions exist on whether the coexistence of IBD (both ulcerative colitis and Crohn's disease) and colonic and rectal NEN is only coincidental. According to some authors [120], an apparent high rate of incidental NENs in IBD patients could be explained only because they frequently undergo intestinal surgery. Indeed, adjusted for resection type, sex and age, a lower prevalence of NENs in IBD patients has been reported compared to non-IBD patients (diverticulitis or ischemic).

Other studies reported an increased risk (up to 15 times) of intestinal NENs in IBD. While neuroendocrine tumors are more common in segments that are free from inflammation [121, 122], neuroendocrine carcinomas develop mainly in inflamed mucosa [122, 123], just like what it happens for non-neuroendocrine cancer. Although NENs occur in ulcerative colitis [124] as well as during Crohn's disease, some authors are inclined to think that the incidence is higher in Crohn's disease, triggered by prolonged inflammation, even in distant bowel segments [121, 125].

\section{Prognostic value of inflammatory markers in NENs}

In support of a role of inflammation in tumor development and progression, several studies recognized few inflammatory biomarkers as independent prognostic markers in patients with tumors [126]. Most of these data have been recently confirmed in NENs. Neutrophils, the most abundant white blood cell subset, appear to have an active role in tumorigenesis and tumor progression by secreting several cytokines, able to promote tumor cell proliferation, local invasion, angiogenesis and resistance to chemotherapy [127]. On the other hand lymphocytes play an important role in cell-mediated immune response activation. CD4+ T lymphocytes are involved in senescence and cancer immune-surveillance, detecting and eradicating precancerous and cancerous cells, also by activation of CD8+ T lymphocytes. Lymphocyte infiltration is common in NENs, as assessed by immunohistochemistry for CD3, CD4, CD8, and CD56 [39, 128]. In patients with 
intermediate-grade NENs a prominent tumor infiltration of T cells (CD3+) was associated with improved regression free survival, while a low level of infiltrating regulatory $\mathrm{T}$ cells in liver metastases was a predictor of prolonged survival [39].

Neutrophil-to-lymphocyte ratio (NLR) and platelet-to-lymphocyte ratio (PLR) are systemic inflammation markers with a prognostic value in several neoplasms. Some studies addressed the prognostic relevance of NLR and PLR in GEP NENs, demonstrating that these parameters could be useful in identifying patients with a worse outcome $[129,130]$. In a retrospective study including 172 patients with pancreatic NENs, elevated NLR and PLR were both associated with advanced tumor stage and high grade. In the univariate analysis, elevated NLR and PLR were both significantly associated with decreased overall survival and disease free survival, while in the multivariate analysis, the preoperative NLR, but not the PLR, was an independent risk factor. In detail, a preoperative NLR > 2.31 was predictive of significantly worse survival in the subgroup of patients with stage I/II or grade 1/2 tumors. Moreover, predictive models based on both the NLR and conventional stratification systems, such as the WHO classification and AJCC stage, showed improved predictive power as compared to the stratification systems alone [131].

Recently, increased NLR was found to be associated to advanced T stage, lymph node metastasis, tumor thrombus formation and advanced grade in pancreatic NENs. In addition, the recurrence-free survival of these patients with high NLR was significantly lower compared with those with low NLR [132]. Accordingly, in patients with gastric NEN, NLR was an independent prognostic factor for recurrence-free survival and overall survival [133].

The gamma-glutamyltransferase (GGT) level is a biomarker of oxidative stress and correlates with inflammation in the extracellular tissue microenvironment. GGT can play a relevant role in cancer progression and biological behaviour, and is considered a significant prognostic biomarker in several tumors. On the other hand, lymphocytopenia, indicating a state of depressed immune function, could negatively affect survival of cancer patients because of a reduced host response. Therefore, the GGT to lymphocyte ratio index (GLRI) could represent a potentially useful prognostic biomarker in oncology. In a retrospective study including 125 non-functioning pancreatic NENs undergoing curative resection, GLRI was found to be an independent predictor of overall survival and disease free survival. Moreover, preoperative GLRI was associated with advanced tumor stage [134].

$\mathrm{C}$ reactive protein $(\mathrm{CRP})$ is an acute-phase protein, produced in the liver, whose synthesis is triggered by secretion of IL-6 from macrophages and T cells. Any type of chronic or acute inflammatory process can activate acute phase response, making CRP levels a sensitive but unspecific marker. CRP has been shown to be an independent prognostic marker in patients with 
secreting (insulinoma, gastrinoma and other rare functioning tumours) and non-secreting sporadic pancreatic NENs, since it correlated with overall survival. Moreover in univariate Cox regression, pancreatic NEN patients with elevated CRP levels had a significantly higher hazard ratio for death [135].

Angiopoietins (Ang)-1 and -2, and the tyrosine kinase receptor Tie-2 family are involved in angiogenesis that in turn is known to have a key function in tumorigenesis. In addition, this system has a relevant role in the inflammatory processes, with a close loop relationship between angiogenesis and inflammation, particularly in IBD. Interaction of Ang-1 with Tie-2 promotes endothelial cell survival, while Ang-2 exerts a marked pro-angiogenic effect, when VEGF is present, and is involved in chemo-attraction of monocytes in neoplastic tissue. Monocytes expressing Tie-2 and recruited into inflamed or neoplastic tissues can promote angiogenesis. Moreover, there is a soluble form of Tie-2 that has been found increased in several conditions including cancer. GEP NEN patients showed enhanced serum levels of soluble form of Tie-2, Ang1, and Ang-2, compared to age-matched healthy controls. Soluble Tie-2 and Ang-2 levels were significantly higher in GEP NENs with metastases compared to those without metastases. Furthermore, Ang-1, Ang-2, and Tie-2 expression was found to be increased in freshly isolated tumor cells from GEP NEN. Interestingly, an enhanced expression and function of Tie-2 was detected in monocytes from GEP NEN patients. Overall these data would suggest that the Ang/Tie2 system is involved in the growth and dissemination of GEP NENs, also favouring the recruitment of Tie-2(+) monocytes to the tumor site, where they can promote inflammation and angiogenesis [136]. Similarly, Srirajaskanthan R et al. found Ang-2 levels to be increased in patients with well or moderately differentiated NENs, mostly of pancreatic, duodenal or jejunum origin, as compared to healthy controls, and to be significantly higher in presence of metastases as compared to nondisseminated tumours. Moreover patients with higher Ang-2 levels ( $>4756 \mathrm{pg} / \mathrm{ml})$ showed a shorter time to disease progression, overall suggesting a potential prognostic role for Ang-2 in patients with NENs [137].

\section{Therapeutic applications with new checkpoint inhibitors}

Unravelling and understanding the mechanisms implicated in the immune response to neoplasms, induced by tumour-associated antigens, is crucial also in the context of NENs, for gaining new knowledge on tumour biology and for improving the management with the perspective of an immunotherapeutic approach. The therapeutic implications of the involvement of immune system in patients with NENs are known since the introduction of interferon- $\alpha$ biotherapy, which inhibits cell 
cycle progression and hormone synthesis in tumor cells, reduces neoangiogenesis, and activates immune cells [138]. Somatostatin receptors, which are targets widely used for the diagnosis and therapy of NETs [139-142], are also present in immune cells and able to mediate immune and inflammatory reactions [143]. Monocyte-derived cells and mature T-lymphocytes express somatostatin receptors -2 and -3 , respectively. Human lymphoid follicle centers, thymus, and spleen express both receptors as well. In thymus, several evidences suggest the potential physiological role of somatostatin receptors in thymocytes maturation [144]. Although the effects of somatostatin analogues on immune system are not well defined in patients with NETs, these compounds are able to potentiate the cytotoxicity of interleukin- 2 activated peripheral blood mononuclear cells in patients with medullary thyroid cancer [145].

The occurrence of immune response to NENs is demonstrated by the frequent finding of lymphocyte infiltration within the tumour, as discussed in the previous paragraphs. In the view of a potential immunotherapy, specific tumour-associated antigens recognised by CD8+ $\mathrm{T}$ cells have been identified in patients with midgut NENs [128].

NENs can elude immunosurveillance regardless of the immunocompetence of the host. In pancreatic NENs, HLA class I antigen expression was lost or reduced in most of the cases, with the loss of beta-2microglobulin as the most frequent alteration in HLA class I phenotype. HLA class II antigens seemed not to contribute to the biology of NENs, since they were not expressed in all investigated samples [36]. However, in another study, MHC class II expression on pancreatic tumor cells correlated significantly with severity and activity of intratumoral inflammation, as well as with the infiltration of CD4+ T lymphocytes [146].

Anti-tumor immune responses can be impaired by regulatory $\mathrm{T}$ cells. Midgut carcinoid patients exhibited increased frequencies of circulating regulatory $\mathrm{T}$ cells and patients' $\mathrm{T}$ cells were less responsive to polyclonal activation and had a decreased proliferative capacity compared to controls. Moreover, circulating T helper-promoting cytokines were reduced [40].

Programmed death 1 (PD-1), its ligands (PD-L1 and PD-L2) and cytotoxic T-lymphocyte antigen 4 (CTLA-4) are immunosuppressive molecules with a relevant role in the host immune response to tumors, inhibiting T-cell activation. Lamarca A. et al. found that one third of 62 patients with welldifferentiated small intestinal NEN expressed PD-L1 in tumor or tumor-infiltrating lymphocytes [147]. Expression of PD-L1 was observed also in $14 \%$ of tumors and in $27 \%$ of tumor-associated immune cells in patients with poorly-differentiated neuroendocrine carcinomas of the digestive system [148]. In GEP NEN patients, PD-L1 expression was found significantly associated with a high-grade WHO classification (G3) but not with gender, primary site, or lymph node status. Moreover, G3 tumors were characterized by strong PD-L1 expression in intra/peri-tumoral 
infiltrating immune cells [149]. Likewise, in a study of 32 metastatic GEP NEN, the expression of PD-L1, observed in $22 \%$ of patients, was associated with higher WHO tumor grade (grade 3) and had both predictive and prognostic value for survival of patients [150]. In 244 GEP NENs, mostly of the small intestine and pancreas and predominantly G1-G2, high tumor-infiltrating lymphocytes (19.6\%) and high PD-1 (16.1\%) expression significantly correlated with shorter patient survival and with a higher grading. In the same study, expression of PD-L1 (8.7\%) showed a trend toward a shorter patient survival [151]. Furthermore, Sampedro Nunez et al. found PD-1/PD-L1 expressed in 1 to $8 \%$ of GEP NENs. In the same patients, PD-1 tumor expression was higher in metastatic patients, while PD-1 expression in peripheral blood monocytes was associated with tumor progression [152].

Conversely, in 66 patients with GEP NEN, mostly of pancreatic origin, PD-L1 expression was observed in 9\%, while PD-L2 was present in 50\% with no association with disease stage at diagnosis or survival. However, they found an inverse relationship between hypoxia and angiogenesis biomarkers and PD ligands, as PD-L1 positive tumors had lower VEGF-A, Hif-1a and Carbonic Anhydrase (CaIX) expression, while PD-L2 positive tumours had lower CaIX and lower proportion of vascular invasion [153]. Recently, in 102 NENs of duodenum, jejunum and ileum, expression of PD-L1 in $\geq 1 \%$ and $\geq 50 \%$ of tumor cells was found in $39 \%$ and $14 \%$ of cases respectively, with an intratumor host immune response found to be apparently absent in $34 \%$ and intense in $21 \%$ of cases. PD-L1 expression and extent of immune infiltration were significantly higher in duodenal as compared with jejunal/ileal NENs. However, neither PD-L1 expression nor the degree of immune infiltration showed any prognostic significance [154].

Antibodies targeting PD-1 (pembrolizumab, nivolumab, PDR001, JS001), PD-L1 (avelumab, durvalumab) or CTLA-4 (ipilimumab, tremelimumab) have been recently used in several cancers with promising results, and few trials are now in progress for GEP NENs (table 1). In a phase Ib study (KEYNOTE-028), that included patients with various advanced solid tumors, pembrolizumab $(10 \mathrm{mg} / \mathrm{kg}$ every 2 weeks) resulted in an objective response rate of $12 \%$ out of 25 advanced PD-L1positive carcinoid patients and $6 \%$ out of 16 pancreatic NEN patients. None of the carcinoid and pancreatic NEN patients reached complete remission, whereas $60 \%$ and $88 \%$ of the patients, respectively, had stable disease [155].

Taking into consideration that, in some studies, PD-1/PD-L1 expression appears to correlate with higher NEN grade and with reduced survival, immunotherapy targeting this system might be interesting for this subgroup of tumors with a poor prognosis. Nevertheless, more knowledge about the composite immune landscape of these heterogeneous tumors needs to be gained in order to identify the subset of NEN patients most likely to benefit from immunotherapeutic approach. 


\section{Conclusions}

Several evidences suggest a relationship between neuroendocrine system and inflammation, which in turn can play a relevant role in tumorigenesis. Inflammatory mediators, which are produced by the NEN or as part of the host innate immune response, can favour angiogenesis, cancer progression and metastatic spread, and can promote immune editing. On the other hand, a balanced immune system represents a relevant step in cancer prevention through the elimination of dysplastic and cancer cells. Therefore, an inflammatory response may be both pro- and anti-tumorigenic.

Although several studies reported an increased risk of GEP NENs in patients with gastrointestinal inflammatory diseases (chronic atrophic gastritis, chronic pancreatitis, celiac disease, Crohn's disease and ulcerative colitis), most of these studies are retrospective and characterized by potential biases. Therefore, further studies are required to improve the level of evidence, particularly concerning the association between NENs and IBD.

The modulation of the TME may represent an innovative therapeutic strategy in G3 NENs, through the use of checkpoint inhibitors binding to PD-1, PD-L1 or CTLA-4, thereby preventing tumors to evade the immune system. This aspect will be further defined with the completion of several ongoing clinical trials. 


\section{Acknowledgements}

This review is part of the 'Neuroendocrine Tumors Innovation Knowledge and Education' project led by Prof. Annamaria Colao and Prof. Antongiulio Faggiano, which aims at increasing the knowledge on NET.

We would like to acknowledge all the Collaborators of the "NIKE" project: Albertelli M., Altieri B., Ambrosetti E., Bianchi A., Bottiglieri L., Campione S., De Cicco F., Di Dato C., Di Molfetta S., Fanciulli G., Gallo M., Giannetta E., Grillo F., Grossrubatscher E., Guarnotta V., Lo Calzo F., Malandrino P., Martini C., Messina E., Modica R., Muscogiuri G., Pizza G., Razzore P., Rizza L., Rubino M., Ruggeri R., Sciammarella C., Zatelli M.C.

\section{Conflict of interest statement}

A. Colao and A. Faggiano has received consultant fees from Novartis and Ipsen. G. Vitale has received consultant fees from Novartis.

\section{Funding source}

This work was supported by the Italian Ministry of Education, University and Research (MIUR): PRIN 2017Z3N3YC. 


\section{Figure legends:}

Figure 1: Components of tumor microenvironment and their role in carcinogenesis and tumor progression through modulation of inflammation.

Figure 2: Gastric hyperplastic changes of ECL cells. (a) A mild atrophic gastritis is shown (hematoxylin and eosin stain, 10x magnification). (b) At higher magnification (hematoxylin and eosin stain, 20x magnification), few cells with a clear perinuclear halo can be observed (arrows). (c) They are more evident on immunohistochemistry with chromogranin (20x magnification): neuroendocrine cells display both linear (arrow) and micronodular arrangement (*).

Figure 3: Pseudohypertophy of neuroendocrine cells in chronic pancreatitis. (a) An example of chronic pancreatitis, where exocrine pancreatic tissue is partially replaced by fibrosis (hematoxylin and eosin stain, 20x magnification). (b) Langerhans islands seem to be hyperplastic and more evident on immunohistochemistry with chromogranin (20x magnification).

Figure 4: Inflammatory bowel diseases and NEN. (a) The rectal submucosa was occupied by a neuroendocrine carcinoma (positive to chromogranin) in a patient with a history of ulcerative colitis of at least 20 years. In the mucosa overlying the neoplastic lesion, neuroendocrine cells were normally represented (20x magnification). (b) Far from this lesion, an increased number of neuroendocrine cells was detected (40 x magnification). 


\section{References}

[1] Walenkamp A, Crespo G, Fierro Maya F, Fossmark R, Igaz P, Rinke A, et al. Hallmarks of gastrointestinal neuroendocrine tumours: implications for treatment. Endocrine-related cancer. 2014;21:R44560.10.1530/ERC-14-0106

[2] Giannetta E, Guarnotta V, Rota F, de Cicco F, Grillo F, Colao A, et al. A rare rarity: Neuroendocrine tumor of the esophagus. Critical reviews in oncology/hematology. 2019;137:92107.10.1016/j.critrevonc.2019.02.012

[3] Wang M, Zhao J, Zhang L, Wei F, Lian Y, Wu Y, et al. Role of tumor microenvironment in tumorigenesis. Journal of Cancer. 2017;8:761-73.10.7150/jca.17648

[4] Cuny T, de Herder W, Barlier A, Hofland L. Role of the tumor microenvironment in digestive neuroendocrine tumors. Endocrine-related cancer. 2018;25:R519-R44.10.1530/ERC-18-0025

[5] Zhang WH, Wang WQ, Gao HL, Yu XJ, Liu L. The tumor immune microenvironment in gastroenteropancreatic neuroendocrine neoplasms. Biochimica et biophysica acta Reviews on cancer. 2019;1872:188311.10.1016/j.bbcan.2019.188311

[6] Carmeliet P, Jain RK. Angiogenesis in cancer and other diseases. Nature. 2000;407:24957.10.1038/35025220

[7] La Rosa S, Uccella S, Finzi G, Albarello L, Sessa F, Capella C. Localization of vascular endothelial growth factor and its receptors in digestive endocrine tumors: correlation with microvessel density and clinicopathologic features. Human pathology. 2003;34:18-27.10.1053/hupa.2003.56

[8] Angelescu R, Burada F, Angelescu C, Gheonea DI, lordache S, Mixich F, et al. Expression of vascular endothelial growth factor and epidermal growth factor receptor in pancreatic ductal adenocarcinomas, neuroendocrine tumours and chronic pancreatitis. Endoscopic ultrasound. 2013;2:86-91.10.4103/23039027.117692

[9] Cigrovski Berkovic M, Cacev T, Catela Ivkovic T, Marout J, Ulamec M, Zjacic-Rotkvic V, et al. High VEGF serum values are associated with locoregional spread of gastroenteropancreatic neuroendocrine tumors (GEP-NETs). Molecular and cellular endocrinology. 2016;425:61-8.10.1016/j.mce.2016.01.013

[10] Inoue M, Hager JH, Ferrara N, Gerber HP, Hanahan D. VEGF-A has a critical, nonredundant role in angiogenic switching and pancreatic beta cell carcinogenesis. Cancer cell. 2002;1:193-202.10.1016/S15356108(02)00031-4

[11] Lawson ND, Weinstein BM. In vivo imaging of embryonic vascular development using transgenic zebrafish. Developmental biology. 2002;248:307-18.10.1006/dbio.2002.0711

[12] Gaudenzi G, Albertelli M, Dicitore A, Wurth R, Gatto F, Barbieri F, et al. Patient-derived xenograft in zebrafish embryos: a new platform for translational research in neuroendocrine tumors. Endocrine. 2017;57:214-9.10.1007/s12020-016-1048-9

[13] Gaudenzi G, Vitale G. Transplantable zebrafish models of neuroendocrine tumors. Annales d'endocrinologie. 2019;80:149-52.10.1016/j.ando.2019.04.013

[14] Vitale G, Gaudenzi G, Dicitore A, Cotelli F, Ferone D, Persani L. Zebrafish as an innovative model for neuroendocrine tumors. Endocrine-related cancer. 2014;21:R67-83.10.1530/ERC-13-0388

[15] Lu P, Takai K, Weaver VM, Werb Z. Extracellular matrix degradation and remodeling in development and disease. Cold Spring Harbor perspectives in biology. 2011;3.10.1101/cshperspect.a005058

[16] Garcia-Suarez O, Garcia B, Fernandez-Vega I, Astudillo A, Quiros LM. Neuroendocrine tumors show altered expression of chondroitin sulfate, glypican 1, glypican 5 , and syndecan 2 depending on their differentiation grade. Frontiers in oncology. 2014;4:15.10.3389/fonc.2014.00015

[17] Garcia B, Garcia-Suarez O, Fernandez-Vega I, Vallina A, Astudillo A, Quiros LM. Heparanase and heparanase 2 display differently deregulation in neuroendocrine tumors, depending on their differentiation grade. Histology and histopathology. 2016;31:73-81.10.14670/HH-11-650

[18] Arcucci A, Ruocco MR, Granato G, Sacco AM, Montagnani S. Cancer: An Oxidative Crosstalk between Solid Tumor Cells and Cancer Associated Fibroblasts. Biomed Res Int. 2016;2016:4502846.10.1155/2016/4502846

[19] Avagliano A, Granato G, Ruocco MR, Romano V, Belviso I, Carfora A, et al. Metabolic Reprogramming of Cancer Associated Fibroblasts: The Slavery of Stromal Fibroblasts. Biomed Res Int. 2018;2018:6075403.10.1155/2018/6075403 
[20] Dimmeler S, Zeiher AM. Netting Insights into Fibrosis. New Engl J Med. 2017;376:14757.10.1056/Nejmcibr1616598

[21] Laskaratos FM, Rombouts K, Caplin M, Toumpanakis C, Thirlwell C, Mandair D. Neuroendocrine tumors and fibrosis: An unsolved mystery? Cancer. 2017;123:4770-90.10.1002/cncr.31079

[22] Daskalakis K, Karakatsanis A, Stalberg P, Norlen O, Hellman P. Clinical signs of fibrosis in small intestinal neuroendocrine tumours. The British journal of surgery. 2017;104:69-75.10.1002/bjs.10333

[23] Gustafsson BI, Hauso O, Drozdov I, Kidd M, Modlin IM. Carcinoid heart disease. International journal of cardiology. 2008;129:318-24.10.1016/j.ijcard.2008.02.019

[24] van der Horst-Schrivers AN, Wymenga AN, Links TP, Willemse PH, Kema IP, de Vries EG. Complications of midgut carcinoid tumors and carcinoid syndrome. Neuroendocrinology. 2004;80 Suppl 1:2832.10.1159/000080737

[25] Qu X, Tang Y, Hua S. Immunological Approaches Towards Cancer and Inflammation: A Cross Talk. Frontiers in immunology. 2018;9:563.10.3389/fimmu.2018.00563

[26] Mantovani A, Romero P, Palucka AK, Marincola FM. Tumour immunity: effector response to tumour and role of the microenvironment. Lancet. 2008;371:771-83.10.1016/S0140-6736(08)60241-X

[27] Schetter AJ, Heegaard NH, Harris CC. Inflammation and cancer: interweaving microRNA, free radical, cytokine and p53 pathways. Carcinogenesis. 2010;31:37-49.10.1093/carcin/bgp272

[28] Shankaran V, Ikeda H, Bruce AT, White JM, Swanson PE, Old LJ, et al. IFNgamma and lymphocytes prevent primary tumour development and shape tumour immunogenicity. Nature. 2001;410:110711.10.1038/35074122

[29] Finn OJ. Immuno-oncology: understanding the function and dysfunction of the immune system in cancer. Annals of oncology : official journal of the European Society for Medical Oncology. 2012;23 Suppl 8:viii6-9.10.1093/annonc/mds256

[30] Whiteside TL. The tumor microenvironment and its role in promoting tumor growth. Oncogene. 2008;27:5904-12.10.1038/onc.2008.271

[31] Coussens LM, Werb Z. Inflammation and cancer. Nature. 2002;420:860-7.10.1038/nature01322

[32] Balkwill F, Charles KA, Mantovani A. Smoldering and polarized inflammation in the initiation and promotion of malignant disease. Cancer cell. 2005;7:211-7.10.1016/j.ccr.2005.02.013

[33] Hanahan D, Coussens LM. Accessories to the crime: functions of cells recruited to the tumor microenvironment. Cancer cell. 2012;21:309-22.10.1016/j.ccr.2012.02.022

[34] Katz SC PV, Bamboat ZM, Shia J, Hedvat C, Gonen M et al. T cell infiltrate predicts longterm survival following resection of colorectal cancer liver metastases. Ann Surg Oncol 2009;16:2524-30.

[35] Roncati L, Manenti, A., Pusiol, T., Piscioli, F., Barbolini, G. The lymphocytic inflammation correlates with metastatic risk in carcinoid tumours. Inflamm Cell Signal. 2015;2:1-5.10.14800/ics.1049

[36] Ryschich E, Autschbach, F., Eisold, S., Klar, E., Buchler, M.W., Schmidt, J. Expression of HLA class I/II antigens and $T$ cell immune response in human neuroendocrine tumours of the pancreas. Tissue Antigens. 2003;62:48-54.10.1034/j.1399-0039.2003.00075.x

[37] da Silva A, Bowden M, Zhang S, Masugi Y, Thorner AR, Herbert ZT, et al. Characterization of the Neuroendocrine Tumor Immune Microenvironment. Pancreas. 2018;47:11239.10.1097/MPA.0000000000001150

[38] Wang Y, Ma Y, Fang Y, Wu S, Liu L, Fu D, et al. Regulatory T cell: a protection for tumour cells. Journal of cellular and molecular medicine. 2012;16:425-36.10.1111/j.1582-4934.2011.01437.x

[39] Katz SC, Donkor C, Glasgow K, Pillarisetty VG, Gonen M, Espat NJ, et al. T cell infiltrate and outcome following resection of intermediate-grade primary neuroendocrine tumours and liver metastases. HPB : the official journal of the International Hepato Pancreato Biliary Association. 2010;12:674-83.10.1111/j.14772574.2010.00231.x

[40] Vikman S, Sommaggio R, De La Torre M, Oberg K, Essand M, Giandomenico V, et al. Midgut carcinoid patients display increased numbers of regulatory $T$ cells in peripheral blood with infiltration into tumor tissue. Acta Oncol. 2009;48:391-400.10.1080/02841860802438495

[41] Hao NB, Lu MH, Fan YH, Cao YL, Zhang ZR, Yang SM. Macrophages in tumor microenvironments and the progression of tumors. Clinical \& developmental immunology.

2012;2012:948098.10.1155/2012/948098 
[42] Schiavoni G, Gabriele L, Mattei F. The tumor microenvironment: a pitch for multiple players. Frontiers in oncology. 2013;3:90.10.3389/fonc.2013.00090

[43] Blaylock RL. Cancer microenvironment, inflammation and cancer stem cells: A hypothesis for a paradigm change and new targets in cancer control. Surgical neurology international. 2015;6:92.10.4103/2152-7806.157890

[44] Di Caro G, Cortese N, Castino GF, Grizzi F, Gavazzi F, Ridolfi C, et al. Dual prognostic significance of tumour-associated macrophages in human pancreatic adenocarcinoma treated or untreated with chemotherapy. Gut. 2016;65:1710-20.10.1136/gutjnl-2015-309193

[45] Pyonteck SM, Gadea BB, Wang HW, Gocheva V, Hunter KE, Tang LH, et al. Deficiency of the macrophage growth factor CSF-1 disrupts pancreatic neuroendocrine tumor development. Oncogene. 2012;31:1459-67.10.1038/onc.2011.337

[46] Wei IH, Harmon CM, Arcerito M, Cheng DF, Minter RM, Simeone DM. Tumor-associated macrophages are a useful biomarker to predict recurrence after surgical resection of nonfunctional pancreatic neuroendocrine tumors. Annals of surgery. 2014;260:1088-94.10.1097/SLA.0000000000000262

[47] Krug S, Abbassi R, Griesmann H, Sipos B, Wiese D, Rexin P, et al. Therapeutic targeting of tumorassociated macrophages in pancreatic neuroendocrine tumors. International journal of cancer. 2018;143:1806-16.10.1002/ijc.31562

[48] Cai L, Michelakos T, Deshpande V, Arora KS, Yamada T, Ting DT, et al. Role of Tumor-Associated Macrophages in the Clinical Course of Pancreatic Neuroendocrine Tumors (PanNETs). Clinical cancer research : an official journal of the American Association for Cancer Research. 2019;25:264455.10.1158/1078-0432.CCR-18-1401

[49] Tran Janco JM, Lamichhane P, Karyampudi L, Knutson KL. Tumor-infiltrating dendritic cells in cancer pathogenesis. Journal of immunology. 2015;194:2985-91.10.4049/jimmunol.1403134

[50] Karthaus N, Torensma R, Tel J. Deciphering the message broadcast by tumor-infiltrating dendritic cells. The American journal of pathology. 2012;181:733-42.10.1016/j.ajpath.2012.05.012

[51] Schott M, Feldkamp J, Lettmann M, Simon D, Scherbaum WA, Seissler J. Dendritic cell immunotherapy in a neuroendocrine pancreas carcinoma. Clinical endocrinology. 2001;55:271-7.10.1046/j.13652265.2001.01293.x

[52] Papewalis C, Jacobs B, Wuttke M, Ullrich E, Baehring T, Fenk R, et al. IFN-alpha skews monocytes into CD56+-expressing dendritic cells with potent functional activities in vitro and in vivo. Journal of immunology. 2008;180:1462-70.10.4049/jimmunol.180.3.1462

[53] Papewalis C, Jacobs B, Baran AM, Ehlers M, Stoecklein NH, Willenberg HS, et al. Increased numbers of tumor-lysing monocytes in cancer patients. Molecular and cellular endocrinology. 2011;337:5261.10.1016/j.mce.2011.01.020

[54] Fang F, Xiao W, Tian Z. NK cell-based immunotherapy for cancer. Seminars in immunology. 2017;31:3754.10.1016/j.smim.2017.07.009

[55] Lopez-Soto A, Gonzalez S, Smyth MJ, Galluzzi L. Control of Metastasis by NK Cells. Cancer cell. 2017;32:135-54.10.1016/j.ccell.2017.06.009

[56] Aparicio-Pages MN, Verspaget HW, Pena AS, Lamers CB. Natural killer cell activity in patients with adenocarcinoma in the upper gastrointestinal tract. Journal of clinical \& laboratory immunology. 1991;35:27-32

[57] Zimmer P, Bloch W, Kieven M, Lovenich L, Lehmann J, Holthaus M, et al. Serotonin Shapes the Migratory Potential of NK Cells - An in vitro Approach. International journal of sports medicine. 2017;38:857-63.10.1055/s-0043-113042

[58] Betten A, Dahlgren C, Hermodsson S, Hellstrand K. Serotonin protects NK cells against oxidatively induced functional inhibition and apoptosis. Journal of leukocyte biology. 2001;70:6572.10.1189/jlb.70.1.65

[59] Visconti R, Grieco D. New insights on oxidative stress in cancer. Current opinion in drug discovery \& development. 2009;12:240-5

[60] Cigrovski Berkovic M, Cacev T, Catela Ivkovic T, Zjacic-Rotkvic V, Kapitanovic S. New insights into the role of chronic inflammation and cytokines in the etiopathogenesis of gastroenteropancreatic neuroendocrine tumors. Neuroendocrinology. 2014;99:75-84.10.1159/000362339 
[61] Berkovic MC, Jokic, M., Marout, J., Radosevic, S., Zjacic-Rotkvic, V., Kapitanovic, S. IL-2 -330 T/G SNP and serum values - potential new tumour markers in neuroendocrine tumours of the gastrointestinal tract and pancreas (GEP-NETs). J Mol Med 2010;88:423-9.10.1007/s00109-009-0581-x. Epub 2010 Jan 5.

[62] Berkovic M, Cacev T, Zjacic-Rotkvic V, Kapitanovic S. TNF-alpha promoter single nucleotide polymorphisms in gastroenteropancreatic neuroendocrine tumors. Neuroendocrinology. 2006;84:34652.10.1159/000097988

[63] Pavel ME, Hassler G, Baum U, Hahn EG, Lohmann T, Schuppan D. Circulating levels of angiogenic cytokines can predict tumour progression and prognosis in neuroendocrine carcinomas. Clinical endocrinology. 2005;62:434-43.10.1111/j.1365-2265.2005.02238.x

[64] Maja Cigrovski Berković MJ, Jasminka Marout, Senka Radošević, Vanja Zjačić-Rotkvić, Sanja Kapitanović IL-6-174 C/G polymorphism in the gastroenteropancreatic neuroendocrine tumors (GEP-NETs). Experimental and Molecular Pathology. 2007;83:474-9

[65] Qian BF, El-Salhy M, Melgar S, Hammarstrom ML, Danielsson A. Neuroendocrine changes in colon of mice with a disrupted IL-2 gene. Clinical and experimental immunology. 2000;120:424-33

[66] Berkovic MC, Jokic M, Marout J, Radosevic S, Zjacic-Rotkvic V, Kapitanovic S. IL-6-174 C/G polymorphism in the gastroenteropancreatic neuroendocrine tumors (GEP-NETs). Exp Mol Pathol. 2007;83:474-9.10.1016/j.yexmp.2007.08.018

[67] Cigrovski Berkovic M, Catela Ivkovic T, Marout J, Zjacic-Rotkvic V, Kapitanovic S. Interleukin 1beta gene single-nucleotide polymorphisms and susceptibility to pancreatic neuroendocrine tumors. DNA and cell biology. 2012;31:531-6.10.1089/dna.2011.1317

[68] Delle Fave G, Corleto VD. Oncogenes, growth factors, receptor expression and proliferation markers in digestive neuroendocrine tumours. A critical reappraisal. Annals of oncology : official journal of the European Society for Medical Oncology. 2001;12 Suppl 2:S13-7.10.1093/annonc/12.suppl_2.s13

[69] Höpfner M, Schuppan, D., Scherübl, H. Treatment of gastrointestinal neuroendocrine tumors with inhibitors of growth factor receptors and their signaling pathways: Recent advances and future perspectives. World journal of gastroenterology. 2008;14:2461- 73. 10.3748/wjg.14.2461

[70] Wulbrand U, Wied, M., Zofel, P., Goke, B., Arnold, R., Fehmann, H.C. Growth factor receptor expression in human gastroenteropancreatic neuroendocrine tumors. European J of Clin Invest 1998;28:103849.10.1046/j.1365-2362.1998.00397.x

[71] Berković MC, Mahečić, D.H., Tomašić, V., Hrabar, D., and Zjačić-Rotkvić, V. The Association of Chronic Inflammation and Gastroenteropancreatic Neuroendocrine Tumors (GEP-NETs). Neuroendocrine Tumor 2012.10.5772/34482

[72] Osipo C, Golde TE, Osborne BA, Miele LA. Off the beaten pathway: the complex cross talk between Notch and NF-kappaB. Laboratory investigation; a journal of technical methods and pathology. 2008;88:117.10.1038/labinvest.3700700

[73] Crabtree JS, Singleton CS, Miele L. Notch Signaling in Neuroendocrine Tumors. Frontiers in oncology. 2016;6:94.10.3389/fonc.2016.00094

[74] Briest F, Berg E, Grass I, Freitag H, Kaemmerer D, Lewens F, et al. FOXM1: A novel drug target in gastroenteropancreatic neuroendocrine tumors. Oncotarget. 2015;6:8185-99.10.18632/oncotarget.3600

[75] Harris RE. Cyclooxygenase-2 (cox-2) blockade in the chemoprevention of cancers of the colon, breast, prostate, and lung. Inflammopharmacology. 2009;17:55-67.10.1007/s10787-009-8049-8

[76] Nakajima T, Hamanaka K, Fukuda T, Oyama T, Kashiwabara K, Sano T. Why is cyclooxygenase-2 expressed in neuroendocrine cells of the human alimentary tract? Pathology international. 1997;47:889-91

[77] Cadden I, Johnston BT, Turner G, McCance D, Ardill J, McGinty A. An evaluation of cyclooxygenase-2 as a prognostic biomarker in mid-gut carcinoid tumours. Neuroendocrinology. 2007;86:10411.10.1159/000107555

[78] Ohike N, Morohoshi T. Immunohistochemical analysis of cyclooxygenase (COX)-2 expression in pancreatic endocrine tumors: association with tumor progression and proliferation. Pathology international. 2001;51:770-7.10.1046/j.1440-1827.2001.01273.x

[79] Kim HS, Lee HS, Kim WH. Clinical significance of protein expression of cyclooxygenase-2 and somatostatin receptors in gastroenteropancreatic neuroendocrine tumors. Cancer research and treatment : official journal of Korean Cancer Association. 2011;43:181-8.10.4143/crt.2011.43.3.181 
[80] de Jong PR, Gonzalez-Navajas JM, Jansen NJ. The digestive tract as the origin of systemic inflammation. Critical care. 2016;20:279.10.1186/s13054-016-1458-3

[81] Franceschi C, Garagnani P, Vitale G, Capri M, Salvioli S. Inflammaging and 'Garb-aging'. Trends in endocrinology and metabolism: TEM. 2017;28:199-212.10.1016/j.tem.2016.09.005

[82] Massironi S, Zilli A, Elvevi A, Invernizzi P. The changing face of chronic autoimmune atrophic gastritis: an updated comprehensive perspective. Autoimmunity reviews. 2019;18:215-

22.10.1016/j.autrev.2018.08.011

[83] Campana D, Ravizza D, Ferolla P, Faggiano A, Grimaldi F, Albertelli M, et al. Risk factors of type 1 gastric neuroendocrine neoplasia in patients with chronic atrophic gastritis. A retrospective, multicentre study. Endocrine. 2017;56:633-8.10.1007/s12020-016-1099-y

[84] Murphy G, Dawsey SM, Engels EA, Ricker W, Parsons R, Etemadi A, et al. Cancer Risk After Pernicious Anemia in the US Elderly Population. Clinical gastroenterology and hepatology : the official clinical practice journal of the American Gastroenterological Association. 2015;13:2282-9 e1-4.10.1016/j.cgh.2015.05.040

[85] Vannella L, Sbrozzi-Vanni A, Lahner E, Bordi C, Pilozzi E, Corleto VD, et al. Development of type I gastric carcinoid in patients with chronic atrophic gastritis. Alimentary pharmacology \& therapeutics. 2011;33:1361-9.10.1111/j.1365-2036.2011.04659.x

[86] Kokkola A, Sjoblom SM, Haapiainen R, Sipponen P, Puolakkainen P, Jarvinen H. The risk of gastric carcinoma and carcinoid tumours in patients with pernicious anaemia. A prospective follow-up study. Scandinavian journal of gastroenterology. 1998;33:88-92.10.1080/00365529850166266

[87] Lehtola J, Karttunen T, Krekela I, Niemela S, Rasanen O. Gastric carcinoids with minimal or no macroscopic lesion in patients with pernicious anemia. Hepato-gastroenterology. 1985;32:72-6

[88] Vanoli A, La Rosa S, Luinetti O, Klersy C, Manca R, Alvisi C, et al. Histologic changes in type A chronic atrophic gastritis indicating increased risk of neuroendocrine tumor development: the predictive role of dysplastic and severely hyperplastic enterochromaffin-like cell lesions. Human pathology. 2013;44:182737.10.1016/j.humpath.2013.02.005

[89] Kidd M, Miu K, Tang LH, Perez-Perez GI, Blaser MJ, Sandor A, et al. Helicobacter pylori lipopolysaccharide stimulates histamine release and DNA synthesis in rat enterochromaffin-like cells. Gastroenterology. 1997;113:1110-7.10.1053/gast.1997.v113.pm9322505

[90] Parsons BN, ljaz UZ, D'Amore R, Burkitt MD, Eccles R, Lenzi L, et al. Comparison of the human gastric microbiota in hypochlorhydric states arising as a result of Helicobacter pylori-induced atrophic gastritis, autoimmune atrophic gastritis and proton pump inhibitor use. PLoS pathogens. 2017;13:e1006653.10.1371/journal.ppat.1006653

[91] Judd LM, Gleeson PA, Toh BH, van Driel IR. Autoimmune gastritis results in disruption of gastric epithelial cell development. The American journal of physiology. 1999;277:G20918.10.1152/ajpgi.1999.277.1.G209

[92] Lowenfels AB, Maisonneuve P, Cavallini G, Ammann RW, Lankisch PG, Andersen JR, et al. Pancreatitis and the risk of pancreatic cancer. International Pancreatitis Study Group. The New England journal of medicine. 1993;328:1433-7.10.1056/NEJM199305203282001

[93] Bansal P, Sonnenberg A. Pancreatitis is a risk factor for pancreatic cancer. Gastroenterology. 1995;109:247-51.10.1016/0016-5085(95)90291-0

[94] Capurso G, Falconi M, Panzuto F, Rinzivillo M, Boninsegna L, Bettini R, et al. Risk factors for sporadic pancreatic endocrine tumors: a case-control study of prospectively evaluated patients. The American journal of gastroenterology. 2009;104:3034-41.10.1038/ajg.2009.466

[95] Haugvik SP, Hedenstrom P, Korsaeth E, Valente R, Hayes A, Siuka D, et al. Diabetes, smoking, alcohol use, and family history of cancer as risk factors for pancreatic neuroendocrine tumors: a systematic review and meta-analysis. Neuroendocrinology. 2015;101:133-42.10.1159/000375164

[96] Valente R, Hayes AJ, Haugvik SP, Hedenstrom P, Siuka D, Korsaeth E, et al. Risk and protective factors for the occurrence of sporadic pancreatic endocrine neoplasms. Endocrine-related cancer. 2017;24:40514.10.1530/ERC-17-0040

[97] Swidnicka-Siergiejko AK, Gomez-Chou SB, Cruz-Monserrate Z, Deng D, Liu Y, Huang H, et al. Chronic inflammation initiates multiple forms of K-Ras-independent mouse pancreatic cancer in the absence of TP53. Oncogene. 2017;36:3149-58.10.1038/onc.2016.461 
[98] Solcia E, Vanoli A. Histogenesis and natural history of gut neuroendocrine tumors: present status. Endocrine pathology. 2014;25:165-70.10.1007/s12022-014-9312-0

[99] Di Sabatino A, Giuffrida P, Vanoli A, Luinetti O, Manca R, Biancheri P, et al. Increase in neuroendocrine cells in the duodenal mucosa of patients with refractory celiac disease. The American journal of gastroenterology. 2014;109:258-69.10.1038/ajg.2013.426

[100] Sjolund K, Alumets J, Berg NO, Hakanson R, Sundler F. Duodenal endocrine cells in adult coeliac disease. Gut. 1979;20:547-52.10.1136/gut.20.7.547

[101] Sjolund K, Nobin A. Increased levels of plasma 5-hydroxytryptamine in patients with coeliac disease. Scandinavian journal of gastroenterology. 1985;20:304-8.10.3109/00365528509091655

[102] Ilus T, Kaukinen K, Virta L, Pukkala E, Collin P. Incidence of malignancies in diagnosed celiac patients: a population-based estimate. The American journal of gastroenterology. 2014;109:14717.10.1038/ajg.2014.194

[103] Perez-Cuadrado-Robles E, Lujan-Sanchis M, Elli L, Juanmartinena-Fernandez JF, Garcia-Lledo J, RuanoDiaz $L$, et al. Role of capsule endoscopy in alarm features and non-responsive celiac disease: A European multicenter study. Digestive endoscopy : official journal of the Japan Gastroenterological Endoscopy Society. 2018;30:461-6.10.1111/den.13002

[104] Hallert C, Norrby K. Malignant carcinoid tumour complicating coeliac disease. Acta medica Scandinavica. 1983;213:313-6.10.1111/j.0954-6820.1983.tb03741.x

[105] Gardiner GW, Van Patter T, Murray D. Atypical carcinoid tumor of the small bowel complicating celiac disease. Cancer. 1985;56:2716-22.10.1002/1097-0142(19851201)56:11<2716::aidcncr2820561135>3.0.co;2-I

[106] Kimchi NA, Broide E, Zehavi S, Halevy A, Scapa E. Capsule endoscopy diagnosis of celiac disease and ileal tumors in a patient with melena of obscure origin. The Israel Medical Association journal : IMAJ. 2005;7:412-3

[107] Sottile R, Percopo F, Persico V, Ciacci C. Recidivant midgut neuroendocrine tumor in a celiac patient. The American journal of gastroenterology. 2001;96:608-9.10.1111/j.1572-0241.2001.03575.x

[108] Bojesen RD, Riis LB, Hogdall E, Nielsen OH, Jess T. Inflammatory Bowel Disease and Small Bowel Cancer Risk, Clinical Characteristics, and Histopathology: A Population-Based Study. Clinical gastroenterology and hepatology : the official clinical practice journal of the American Gastroenterological Association. 2017;15:1900-7 e2.10.1016/j.cgh.2017.06.051

[109] Algaba A, Guerra I, Castano A, de la Poza G, Castellano VM, Lopez M, et al. Risk of cancer, with special reference to extra-intestinal malignancies, in patients with inflammatory bowel disease. World journal of gastroenterology. 2013;19:9359-65.10.3748/wjg.v19.i48.9359

[110] Alexandraki KI, Kaltsas GA, Grozinsky-Glasberg S, Chatzellis E, Grossman AB. Appendiceal neuroendocrine neoplasms: diagnosis and management. Endocrine-related cancer. 2016;23:R2741.10.1530/ERC-15-0310

[111] Vasei M, Zakeri Z, Azarpira N, Hosseini SV, Solaymani-Dodaran M. Serotonin content of normal and inflamed appendix: a possible role of serotonin in acute appendicitis. APMIS : acta pathologica, microbiologica, et immunologica Scandinavica. 2008;116:947-52.10.1111/j.1600-0463.2008.00916.x

[112] Szabo GG, Barta Z, Kerekes L, Szakall S. [Association of carcinoid tumor of the appendix and Crohn disease (case report and review of the literature)]. Orvosi hetilap. 1999;140:1635-9

[113] Qiao Y, Yang T, Gan Y, Li W, Wang C, Gong Y, et al. Associations between aspirin use and the risk of cancers: a meta-analysis of observational studies. BMC cancer. 2018;18:288.10.1186/s12885-018-4156-5

[114] Hernandez-Trejo JA, Suarez-Perez D, Gutierrez-Martinez IZ, Fernandez-Vargas OE, Serrano C, Candelario-Martinez AA, et al. The pro-inflammatory cytokines IFNgamma/TNFalpha increase chromogranin A-positive neuroendocrine cells in the colonic epithelium. The Biochemical journal. 2016;473:3805-18.10.1042/BCJ20160390

[115] Laukoetter MG, Nava P, Nusrat A. Role of the intestinal barrier in inflammatory bowel disease. World journal of gastroenterology. 2008;14:401-7.10.3748/wjg.14.401

[116] Fang D, Hawke D, Zheng Y, Xia Y, Meisenhelder J, Nika H, et al. Phosphorylation of beta-catenin by AKT promotes beta-catenin transcriptional activity. The Journal of biological chemistry. 2007;282:112219.10.1074/jbc.M611871200 
[117] Cross DA, Alessi DR, Cohen P, Andjelkovich M, Hemmings BA. Inhibition of glycogen synthase kinase-3 by insulin mediated by protein kinase B. Nature. 1995;378:785-9.10.1038/378785a0

[118] Nava P, Kamekura R, Quiros M, Medina-Contreras O, Hamilton RW, Kolegraff KN, et al. IFNgammainduced suppression of beta-catenin signaling: evidence for roles of Akt and 14.3.3zeta. Molecular biology of the cell. 2014;25:2894-904.10.1091/mbc.E13-09-0512

[119] Shigaki K, Mitomi H, Fujimori T, Ichikawa K, Tomita S, Imura J, et al. Immunohistochemical analysis of chromogranin A and p53 expressions in ulcerative colitis-associated neoplasia: neuroendocrine differentiation as an early event in the colitis-neoplasia sequence. Human pathology. 2013;44:23939.10.1016/j.humpath.2013.06.008

[120] Derikx LA, Vierdag WM, Kievit W, Bosch S, Hoentjen F, Nagtegaal ID. Is the prevalence of colonic neuroendocrine tumors increased in patients with inflammatory bowel disease? International journal of cancer. 2016;139:535-42.10.1002/ijc.30096

[121] West NE, Wise PE, Herline AJ, Muldoon RL, Chopp WV, Schwartz DA. Carcinoid tumors are 15 times more common in patients with Crohn's disease. Inflammatory bowel diseases. 2007;13:112934.10.1002/ibd.20172

[122] Kortbeek J, Kelly JK, Preshaw RM. Carcinoid tumors and inflammatory bowel disease. Journal of surgical oncology. 1992;49:122-6.10.1002/jso.2930490213

[123] Boltin D, Levi Z, Halpern M, Fraser GM. Concurrent small bowel adenocarcinoma and carcinoid tumor in Crohn's disease--case report and literature review. Journal of Crohn's \& colitis. 2011;5:4614.10.1016/j.crohns.2011.04.006

[124] Guadagno E, De Rosa F, Borrelli G, Luglio G, Bucci L, Del Basso De Caro M. High-grade MiNEN in a Long-standing History of Ulcerative Colitis: An Unexpected Evolution. Inflammatory bowel diseases. 2019;25:e38-e9.10.1093/ibd/izy257

[125] Pellino G, Marcellinaro R, Candilio G, De Fatico GS, Guadagno E, Campione S, et al. The experience of a referral centre and literature overview of GIST and carcinoid tumours in inflammatory bowel diseases. International journal of surgery. 2016;28 Suppl 1:S133-41.10.1016/j.ijsu.2015.12.051

[126] Dolan RD, Laird BJA, Horgan PG, McMillan DC. The prognostic value of the systemic inflammatory response in randomised clinical trials in cancer: A systematic review. Critical reviews in oncology/hematology. 2018;132:130-7.10.1016/j.critrevonc.2018.09.016

[127] Liang W, Ferrara N. The Complex Role of Neutrophils in Tumor Angiogenesis and Metastasis. Cancer immunology research. 2016;4:83-91.10.1158/2326-6066.CIR-15-0313

[128] Vikman S, Giandomenico V, Sommaggio R, Oberg K, Essand M, Totterman TH. CD8+ T cells against multiple tumor-associated antigens in peripheral blood of midgut carcinoid patients. Cancer immunology, immunotherapy : Cll. 2008;57:399-409.10.1007/s00262-007-0382-4

[129] Salman T, Kazaz SN, Varol U, Oflazoglu U, Unek IT, Kucukzeybek Y, et al. Prognostic Value of the Pretreatment Neutrophil-to-Lymphocyte Ratio and Platelet-to-Lymphocyte Ratio for Patients with Neuroendocrine Tumors: An Izmir Oncology Group Study. Chemotherapy. 2016;61:2816.10.1159/000445045

[130] Yucel B, Babacan NA, Kacan T, Eren AA, Eren MF, Bahar S, et al. Survival analysis and prognostic factors for neuroendocrine tumors in Turkey. Asian Pacific journal of cancer prevention : APJCP. 2014;14:6687-92.10.7314/APJCP.2013.14.11.6687

[131] Zhou B, Zhan C, Wu J, Liu J, Zhou J, Zheng S. Prognostic Significance of Preoperative Neutrophil-toLymphocyte Ratio in Surgically Resectable Pancreatic Neuroendocrine Tumors. Medical science monitor : international medical journal of experimental and clinical research. 2017;23:557488.10.12659/MSM.907182

[132] Tong Z, Liu L, Zheng $Y$, Jiang W, Zhao P, Fang W, et al. Predictive value of preoperative peripheral blood neutrophil/lymphocyte ratio for lymph node metastasis in patients of resectable pancreatic neuroendocrine tumors: a nomogram-based study. World journal of surgical oncology. 2017;15:108.10.1186/s12957-017-1169-5

[133] Cao LL, Lu J, Lin JX, Zheng CH, Li P, Xie JW, et al. A novel predictive model based on preoperative blood neutrophil-to-lymphocyte ratio for survival prognosis in patients with gastric neuroendocrine neoplasms. Oncotarget. 2016;7:42045-58.10.18632/oncotarget.9805 
[134] Zhou B, Zhan C, Wu J, Liu J, Zhou J, Zheng S. Prognostic significance of preoperative gammaglutamyltransferase to lymphocyte ratio index in nonfunctional pancreatic neuroendocrine tumors after curative resection. Scientific reports. 2017;7:13372.10.1038/s41598-017-13847-6

[135] Wiese D, Kampe K, Waldmann J, Heverhagen AE, Bartsch DK, Fendrich V. C-Reactive Protein as a New Prognostic Factor for Survival in Patients With Pancreatic Neuroendocrine Neoplasia. The Journal of clinical endocrinology and metabolism. 2016;101:937-44.10.1210/jc.2015-3114

[136] Figueroa-Vega N, Diaz A, Adrados M, Alvarez-Escola C, Paniagua A, Aragones J, et al. The association of the angiopoietin/Tie-2 system with the development of metastasis and leukocyte migration in neuroendocrine tumors. Endocrine-related cancer. 2010;17:897-908.10.1677/ERC-10-0020

[137] Srirajaskanthan R, Dancey G, Hackshaw A, Luong T, Caplin ME, Meyer T. Circulating angiopoietin-2 is elevated in patients with neuroendocrine tumours and correlates with disease burden and prognosis. Endocrine-related cancer. 2009;16:967-76.10.1677/ERC-09-0089

[138] Oberg K, Ferone D, Kaltsas G, Knigge UP, Taal B, Plockinger U, et al. ENETS Consensus Guidelines for the Standards of Care in Neuroendocrine Tumors: biotherapy. Neuroendocrinology. 2009;90:20913.10.1159/000183751

[139] Treglia G, Kroiss AS, Piccardo A, Lococo F, Santhanam P, Imperiale A. Role of positron emission tomography in thyroid and neuroendocrine tumors. Minerva endocrinologica. 2018;43:34155.10.23736/S0391-1977.17.02742-0

[140] Fuentes-Fayos AC, Garcia-Martinez A, Herrera-Martinez AD, Jimenez-Vacas JM, Vazquez-Borrego MC, Castano JP, et al. Molecular determinants of the response to medical treatment of growth hormone secreting pituitary neuroendocrine tumors. Minerva endocrinologica. 2019;44:109-28.10.23736/S03911977.19.02970-5

[141] Vitale G, Dicitore A, Sciammarella C, Di Molfetta S, Rubino M, Faggiano A, et al. Pasireotide in the treatment of neuroendocrine tumors: a review of the literature. Endocrine-related cancer. 2018;25:R351R64.10.1530/ERC-18-0010

[142] Mazziotti G, Mosca A, Frara S, Vitale G, Giustina A. Somatostatin analogs in the treatment of neuroendocrine tumors: current and emerging aspects. Expert opinion on pharmacotherapy. 2017;18:1679-89.10.1080/14656566.2017.1391217

[143] Alonso-Gordoa T, Capdevila J, Grande E. GEP-NETs update: Biotherapy for neuroendocrine tumours. European journal of endocrinology. 2015;172:R31-46.10.1530/EJE-14-0354

[144] Ferone D. Italian Society of Endocrinology Career Award Lecture: from somatostatin to...somatomedin. Journal of endocrinological investigation. 2012;35:869-74.10.3275/8583

[145] Vitale G, Lupoli G, Guarrasi R, Colao A, Dicitore A, Gaudenzi G, et al. Interleukin-2 and lanreotide in the treatment of medullary thyroid cancer: in vitro and in vivo studies. The Journal of clinical endocrinology and metabolism. 2013;98:E1567-74.10.1210/jc.2013-1443

[146] Gaida MM, Welsch T, Herpel E, Tschaharganeh DF, Fischer L, Schirmacher P, et al. MHC class II expression in pancreatic tumors: a link to intratumoral inflammation. Virchows Archiv : an international journal of pathology. 2012;460:47-60.10.1007/s00428-011-1175-x

[147] Lamarca A, Nonaka D, Breitwieser W, Ashton G, Barriuso J, McNamara MG, et al. PD-L1 expression and presence of TILs in small intestinal neuroendocrine tumours. Oncotarget. 2018;9:1492238.10.18632/oncotarget.24464

[148] Roberts JA, Gonzalez RS, Das S, Berlin J, Shi C. Expression of PD-1 and PD-L1 in poorly differentiated neuroendocrine carcinomas of the digestive system: a potential target for anti-PD-1/PD-L1 therapy. Human pathology. 2017;70:49-54.10.1016/j.humpath.2017.10.003

[149] Cavalcanti E, Armentano R, Valentini AM, Chieppa M, Caruso ML. Role of PD-L1 expression as a biomarker for GEP neuroendocrine neoplasm grading. Cell death \& disease. 2017;8:e3004.10.1038/cddis.2017.401

[150] Kim ST, Ha SY, Lee S, Ahn S, Lee J, Park SH, et al. The Impact of PD-L1 Expression in Patients with Metastatic GEP-NETs. Journal of Cancer. 2016;7:484-9.10.7150/jca.13711

[151] Bosch F, Bruwer K, Altendorf-Hofmann A, Auernhammer CJ, Spitzweg C, Westphalen CB, et al. Immune checkpoint markers in gastroenteropancreatic neuroendocrine neoplasia. Endocrine-related cancer. 2019;26:293-301.10.1530/ERC-18-0494 
[152] Sampedro-Nunez M, Serrano-Somavilla A, Adrados M, Cameselle-Teijeiro JM, Blanco-Carrera C, Cabezas-Agricola JM, et al. Analysis of expression of the PD-1/PD-L1 immune checkpoint system and its prognostic impact in gastroenteropancreatic neuroendocrine tumors. Scientific reports. 2018;8:17812.10.1038/s41598-018-36129-1

[153] Pinato DJ, Brown M, White SDT, Zhang H, Toloue S, Dina R, et al. Programmed cell death (PD-1) ligands expression in gastro-entero-pancreatic neuroendocrine tumours (GEP-NETs): relationship with angiogenesis and clinical outcome. Journal of Clinical Oncology. 2016;34:e15658e.10.1200/Jco.2016.34.15_Suppl.E15658

[154] Cives M, Strosberg J, Al Diffalha S, Coppola D. Analysis of the immune landscape of small bowel neuroendocrine tumors. Endocrine-related cancer. 2019;26:119-30.10.1530/ERC-18-0189

[155] Mehnert J.M. RHS, O'Neil B.H., Santoro A., Schellens J.H.M.,Cohen R.B., Doi T., Ott P.A., Pishvaian M.J.,Puzanov I., Aung K.L., Hsu C., Le Tourneau C., Soria J.C.,.Élez E., Tamura K., Gould M., Zaho G., Stein K., PihaPaul S.A. Pembrolizumab for patients with PD-L1-positive advanced carcinoids or pancreatic neuroendocrine tumors: results from the KEYNOTE-028 study. Annals of Oncology. 2017;28:v142v57.10.1093/annonc/mdx368 
Table 1: Ongoing clinical trials of PD-1/PD-L1 or CTLA-4 checkpoint inhibitors in gastroenteropancreatic (GEP) neuroendocrine neoplasms (NENs)

\begin{tabular}{|c|c|c|c|c|}
\hline Study & Phase & Drug & Status & $\begin{array}{c}\text { Clinicaltrials.gov } \\
\text { identifier }\end{array}$ \\
\hline $\begin{array}{l}\text { Open-label study in patients with metastatic } \\
\text { high grade NENs }\end{array}$ & 2 & Pembrolizumab & Recruiting & NCT02939651 \\
\hline $\begin{array}{llll}\begin{array}{l}\text { Recurrent } \\
\text { carcinoma }\end{array} & \text { high } & \text { grade } & \text { neuroendocrine } \\
\end{array}$ & 2 & Pembrolizumab & Active & NCT03190213 \\
\hline $\begin{array}{l}\text { Chemotherapy naïve patients with metastatic } \\
\text { or unresectable high grade GEP or lung } \\
\text { (excluding small cell) neuroendocrine } \\
\text { carcinoma }\end{array}$ & 2 & $\begin{array}{l}\text { Pembrolizumab }+ \\
\text { cisplatin or carboplatin } \\
\quad+\text { etoposide }\end{array}$ & $\begin{array}{c}\text { Not yet } \\
\text { recruiting }\end{array}$ & NCT03901378 \\
\hline High grade neuroendocrine carcinomas & 2 & $\begin{array}{l}\text { Pembrolizumab alone } \\
\text { or Pembrolizumab + } \\
\text { Irinotecan/Paclitaxel }\end{array}$ & Recruiting & NCT03136055 \\
\hline Advanced GEP NENs & $1 / 2$ & $\begin{array}{c}\text { Pembrolizumab }+ \\
\text { Lanreotide depot } 90 \mathrm{mg}\end{array}$ & Recruiting & NCT03043664 \\
\hline $\begin{array}{l}\text { Open-label study in patients with advanced } \\
\text { or metastatic, well-differentiated, non- } \\
\text { functional NENs of pancreatic, } \\
\text { gastrointestinal, or thoracic origin or poorly- } \\
\text { differentiated GEP neuroendocrine } \\
\text { carcinoma, that have progressed on prior } \\
\text { treatment. }\end{array}$ & 2 & PDR001 & Active & NCT02955069 \\
\hline $\begin{array}{l}\text { Advanced NENs following failure of first- } \\
\text { line }\end{array}$ & 1 & JS001 & Recruiting & NCT03167853 \\
\hline $\begin{array}{l}\text { Open-label, single arm study of Nivolumab } \\
\text { in combination with Ipilimumab in subjects } \\
\text { with advanced NENs }\end{array}$ & 2 & $\begin{array}{l}\text { Nivolumab + } \\
\text { Ipilimumab }\end{array}$ & Recruiting & NCT03420521 \\
\hline $\begin{array}{l}\text { A GCO trial exploring the efficacy and safety } \\
\text { of Nivolumab monotherapy or Nivolumab } \\
\text { plus Ipilimumab in pre-treated patients with } \\
\text { advanced, refractory pulmonary or GEP } \\
\text { poorly differentiated neuroendocrine tumors }\end{array}$ & 2 & $\begin{array}{l}\text { Nivolumab +/- } \\
\text { Ipilimumab }\end{array}$ & Recruiting & NCT03591731 \\
\hline $\begin{array}{l}\text { Gastrointestinal, neuro-endocrine and } \\
\text { gynaecological cancers }\end{array}$ & 2 & $\begin{array}{l}\text { Ipilimumab + } \\
\text { Nivolumab }\end{array}$ & Recruiting & NCT02923934 \\
\hline $\begin{array}{l}\text { Recurrent/refractory small-cell lung cancer } \\
\text { and advanced neuroendocrine tumors }\end{array}$ & 2 & $\begin{array}{c}\text { Nivolumab + } \\
\text { Temozolomide }\end{array}$ & Recruiting & NCT03728361 \\
\hline Advanced GEP and pulmonary NENs & 2 & $\begin{array}{l}\text { Durvalumab + } \\
\text { Tremelimumab }\end{array}$ & Recruiting & NCT03095274 \\
\hline $\begin{array}{l}\text { Unresectable/metastatic, progressive grade 2- } \\
3 \text { NENs }\end{array}$ & 2 & Avelumab & Recruiting & NCT03278379 \\
\hline $\begin{array}{l}\text { Advanced, metastatic high grade } \\
\text { neuroendocrine carcinomas (NEC G3) in } \\
\text { progression after first line chemotherapy }\end{array}$ & 2 & Avelumab & Recruiting & NCT03352934 \\
\hline $\begin{array}{l}\text { Unresectable/metastatic, progressive, poorly } \\
\text { differentiated grade } 3 \text { neuroendocrine } \\
\text { carcinomas }\end{array}$ & $1 / 2$ & Avelumab & Recruiting & NCT03278405 \\
\hline $\begin{array}{l}\text { Metastatic GEP neuroendocrine carcinoma } \\
\text { (NEC G3) as second-line treatment after } \\
\text { failing to etoposide+cisplatin: integration of } \\
\text { genomic analysis to identify predictive } \\
\text { molecular subtypes }\end{array}$ & 2 & Avelumab & Recruiting & NCT03147404 \\
\hline
\end{tabular}


CAFs AND EXTRACELLULA
romote excessive local or distant fibrosis

-Favour tumor progression, promoting cellular transformation and metastases

-Deliver oxygen and nutrients

-Contribute to the spread of cancer

-Promote immune cell infiltrating

cell

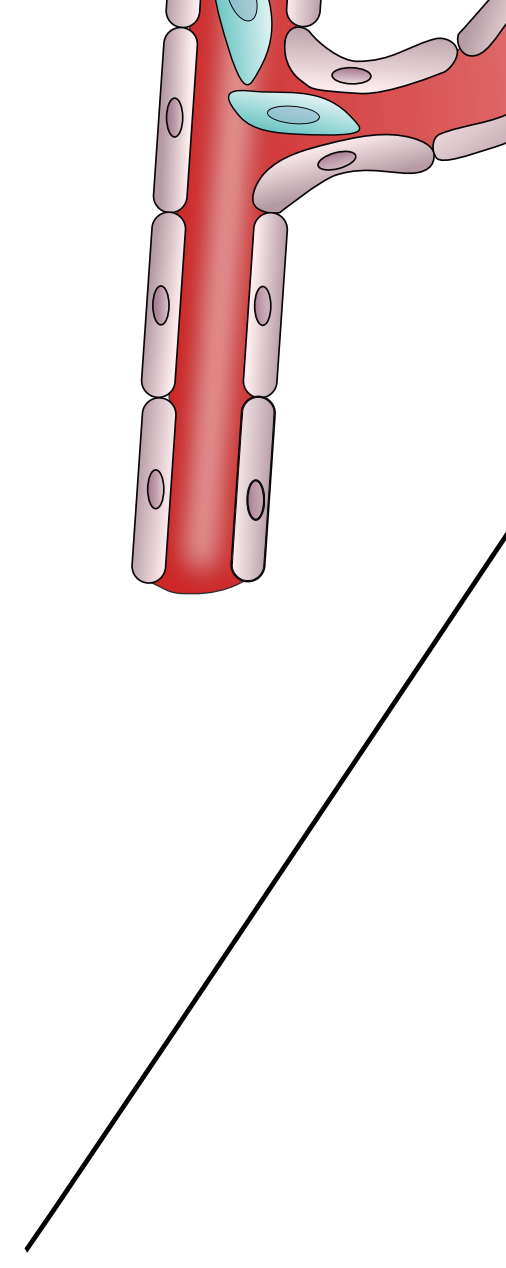

\section{TUMOR-INFILTRATING IMMUNE CELLS}

Macrophages

Lymphocytes

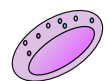

Dendritic cells

Neutrophils

Natural killers

ANTI- AND PRO-TUMOR ROLES:

-Modulate proliferation of cancer and stromal cells

-Release of pro- or anti-inflammatory molecules

-Stimulate angiogenesis

-Facilitate tumor cell dissemination and

-Modulate tumor cell growth

-Promote tumor cell invasion

-Stimulate angiogenesis

-Make tumor cells more resistant to apoptosis

-Maintain a pro-carcinogenic inflammatory TME

Cytokines

Chemokines

NFk-B

STAT3

Cyclooxygenase-2

Reactive oxygen and nitrogen species

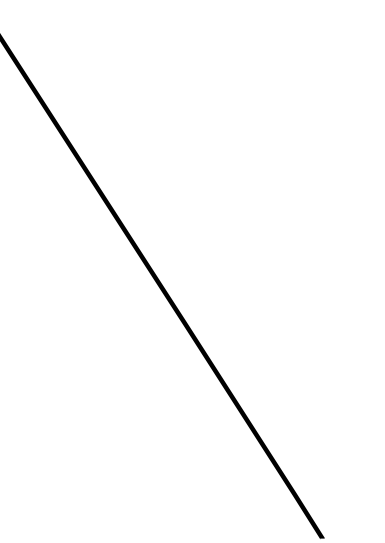


Figure 2

Click here to download high resolution image

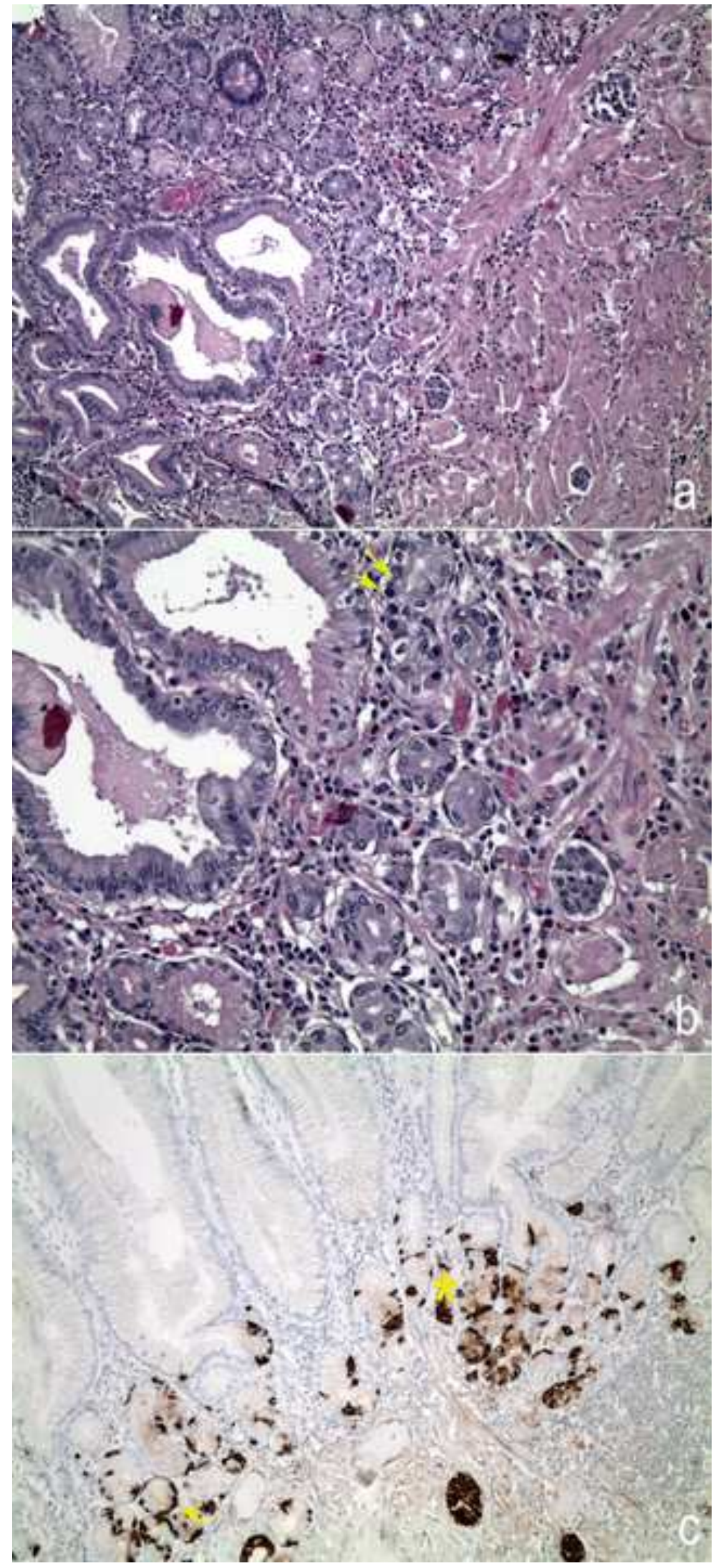




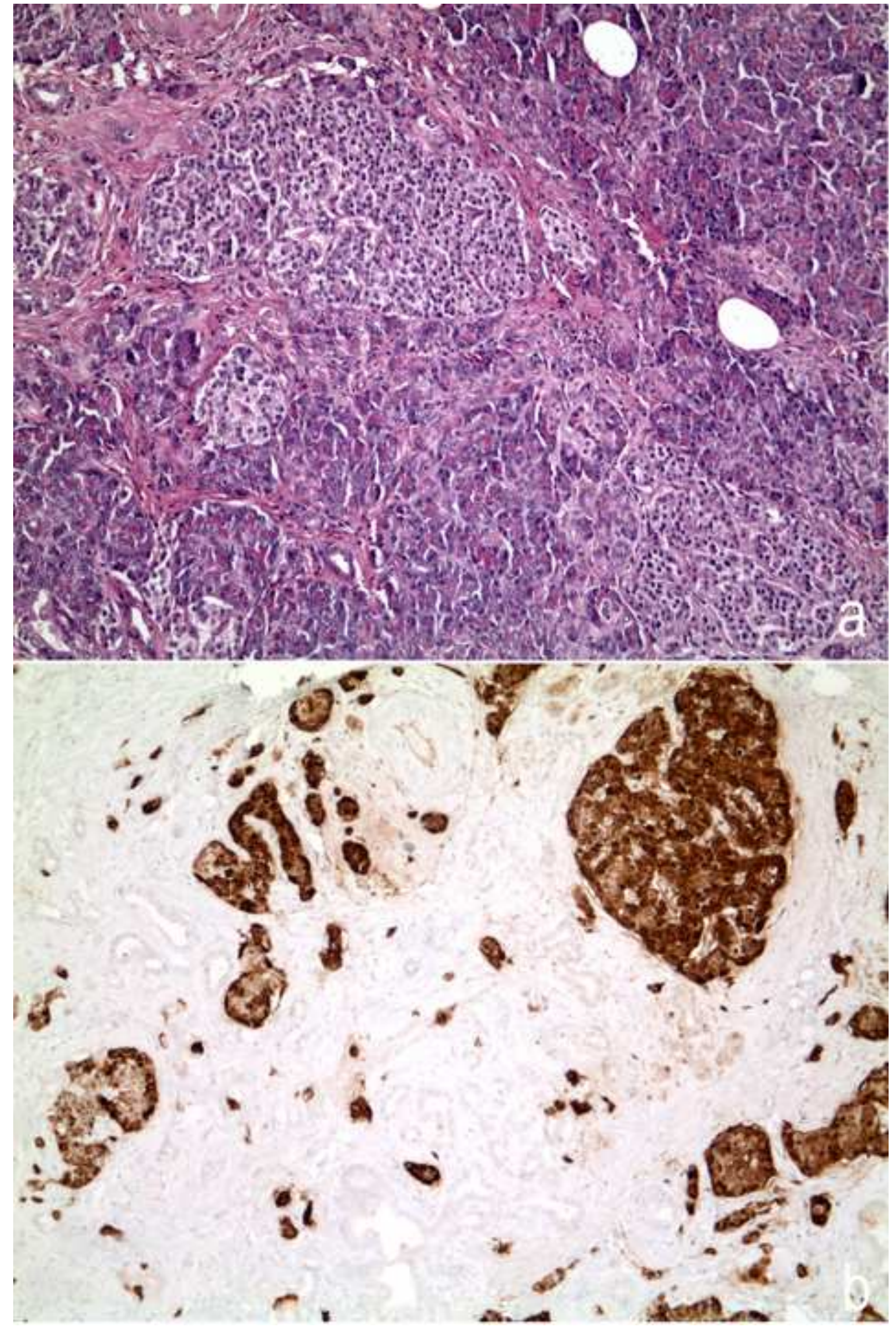




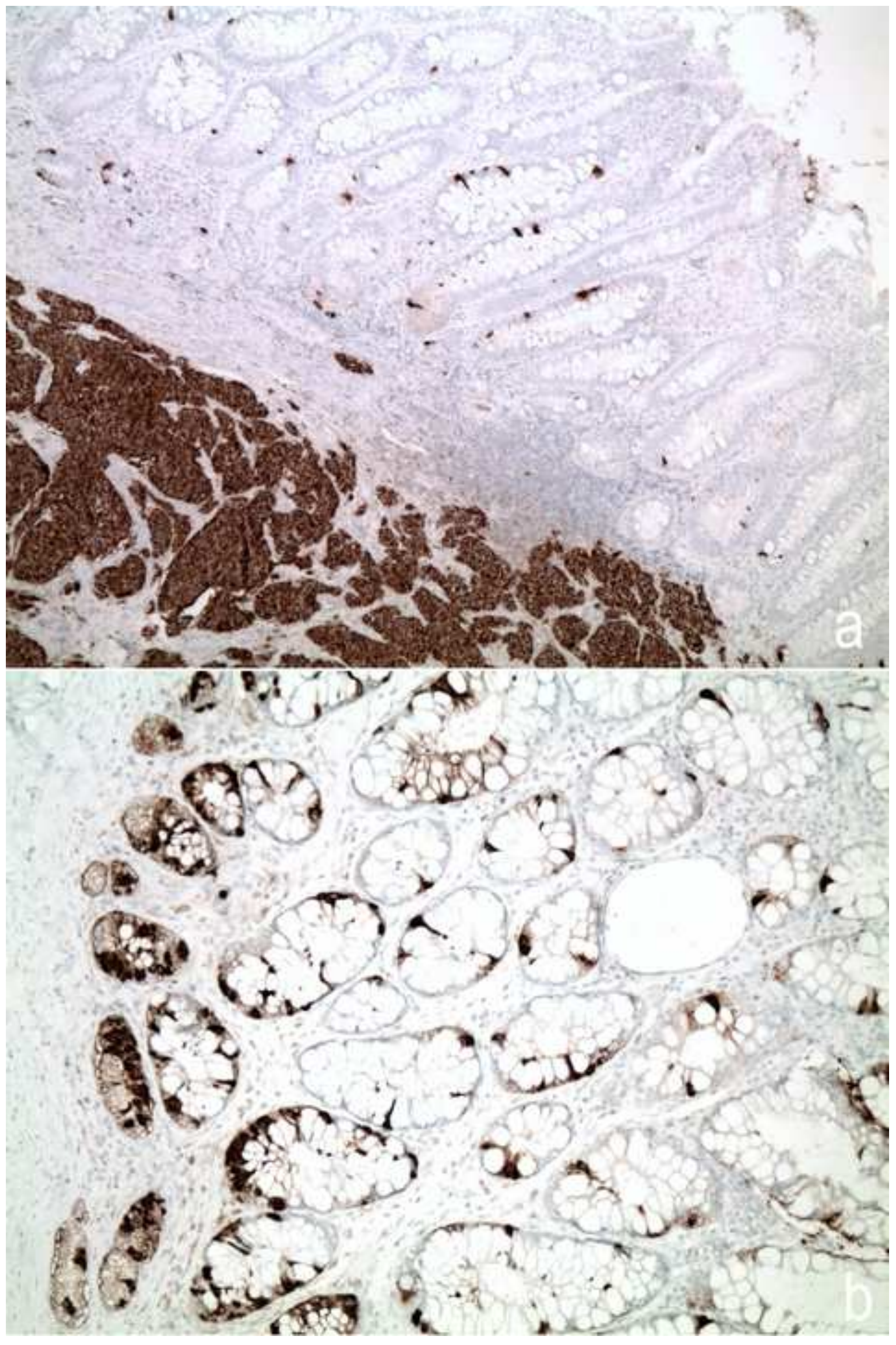


Conflict of Interest Statement

\section{Conflict of interest statement}

A. Colao and A. Faggiano has received consultant fees from Novartis and Ipsen. G. Vitale has received consultant fees from Novartis. 


\title{
Gastroenteropancreatic Neuroendocrine Neoplasms and Inflammation: a Complex Cross-Talk with Relevant Clinical Implications
}

\begin{abstract}
Neuroendocrine neoplasms (NENs) are a group of tumors originating from the neuroendocrine system. They mainly occur in the digestive system and the respiratory tract. It is well-know a strict interaction between neuroendocrine system and inflammation, which can play an important role in NEN carcinogenesis. Inflammatory mediators, which are produced by the tumor microenvironment, can favor cancer induction and progression, and can promote immune editing. On the other hand, a balanced immune system represents a relevant step in cancer prevention through the elimination of dysplastic and cancer cells. Therefore, an inflammatory response may be both pro- and antitumorigenic. In this review, we provide an overview concerning the complex interplay between inflammation and gastroenteropancreatic NENs, focusing on the tumorigenesis and clinical implications in these tumors.
\end{abstract}

Key words: Neuroendocrine tumors, inflammation, tumor microenvironment, immune system, cytokines 


\section{Introduction}

Neuroendocrine neoplasms (NENs) are a group of tumors originating from the neuroendocrine system. NENs develop most commonly in the gastroenteropancreatic (GEP) tract $[1,2]$. Despite the seven-fold increase in NEN incidence in the last four decades, no clear risk factors have been recognized for these tumors. Research over the last decades has underlined the dual role of inflammation in the development and progression of malignancies. Chronic and unbalanced inflammation enhances tumorigenesis. This relationship could be hypothesized also in GEP NEN development, as chronic inflammatory diseases and chronic gastritis are well known predisposing conditions for these tumors. However, under specific inflammatory conditions, immune cells are able to eliminate dysplastic and cancer cells. In this review, we provide an overview concerning the complex interplay between inflammation and GEP NENs, focusing on the tumorigenesis and clinical implications in these tumors.

\section{Role of microenvironment in tumorigenesis and progression of GEP NENs through modulation of inflammation}

The tumor microenvironment (TME) is a dynamic compartment that develops during cancer evolution. TME is not simply constituted by neoplastic cells, but it includes blood and lymphatic vascular networks, extracellular matrix, cancer-associated fibroblasts (CAFs), adipose cells, neuroendocrine cells, immune-inflammatory cells and different molecular players, such as proinflammatory and oncogenic mediators [3]. The interplay between all these elements, in particular the inflammatory microenvironment, is crucial to shape the fate and the evolution of several tumors (figure 1). Although underestimated until now, TME has a relevant role in tumorigenesis, progression and response to the therapy in GEP NENs [4, 5].

\subsection{Vasculature}

Blood and lymphatic vessels deliver nutrients and oxygen, necessary for cancer survival, and are relevant for tumor progression and the development of immune cell infiltration. The hypoxic tumor microenvironment prompts the release of proangiogenic factors, like vascular endothelial growth factor (VEGF), fibroblast growth factor (FGF), platelet-derived growth factor (PDGF) and transforming growth factor $\beta$ (TGF- $\beta$ ), promoting the rapid and aberrant vasculature formation within the tumor [6]. NENs are highly vascularized. The development of new blood vessels involves different proangiogenic factors. The best known and characterized is surely VEGF and its receptors (VEGFRs). VEGF overexpression is generally associated to an increased microvascular 
density, leading to tumor progression. GEP NENs are characterized by a marked expression of VEGF/VEGFRs [7, 8], but the relationship between VEGF, tumor vascularization and prognosis is not straightforward. In gastrointestinal NENs this correlation is unclear, only in pancreatic NENs it has been reported that VEGF expression is higher in benign and low-grade tumors. Therefore, this condition results to be associated to a good prognosis and prolonged survival [9, 10]. A comprehensive explanation for this paradox could be that in pancreatic NENs the vascular density is more likely a marker of differentiation than a marker of aggressiveness. FGF, PDGF and TGF- $\beta$ are also strongly expressed in GEP-NENs [4].

In order to study in vivo the tumor-induced angiogenesis, we have developed an innovative model through the xenograft of human NEN cells into $T g(f l i l a: E G F P)^{y 1}$ [11] zebrafish embryos. This transgenic line, expressing the enhanced green fluorescent protein (EGFP) in the endothelial cells of the entire vascular tree, offers the possibility to estimate the proangiogenic potential of injected tumor cells and to analyze the contribution of the TME to the tumor progression in a living selective microenvironment [12-14].

\subsection{Reactive stromal cells}

Extracellular matrix is structurally constituted by interstitial matrix, which mainly includes stromal cells, and by basement membrane. Extracellular matrix contains soluble molecules, such as chemokines, matrix metalloproteinases, protease inhibitors and growth factors. An abnormal extracellular matrix favors tumor progression, promoting cellular transformation and metastasis [15]. Among different factors involved in extracellular matrix remodeling, proteoglycans play different roles in cancer. In GEP NENs the expression of syndecan 2 and glypican 1 proteoglycans has been reported to be high in well-differentiated tumors. Their levels correlated positively with patient survival [16]. In a recent paper, the prometastatic enzyme heparanase, a glucuronidase, resulted to be overexpressed in well- but not in poorly differentiated NENs [17].

CAFs, a population of activated fibroblasts (also known as myofibroblasts), represent the major non-cancer cells within the tumor stroma. They share properties with fibroblast stimulated by inflammation or wound healing. Indeed, they can secrete a variety of mesenchyme-specific proteins [18], chemokines (CXCL-8 and CXCL-12), cytokines (interleukin-6) and growth factors, including VEGF, TGF- $\beta$, FGF, hepatocyte growth factor and epidermal growth factor (EGF). These factors are involved in paracrine signaling or activate CAFs in autocrine loops. The crosstalk between CAFs and cancer cells is responsible for the promotion and maintaining of the activated phenotype of fibroblasts and, in turn, the production of soluble factors by CAFs fosters the cancer growth and progression, promoting the remodeling of extracellular matrix, cell proliferation and angiogenesis 
[19]. Activated fibroblasts are recruited to the tumor site miming excessive fibrosis, as a consequence of inflammation and aging [20]. It has been observed that NENs are often associated with local or distant fibrosis and that the crosstalk between NEN cells and fibroblasts has a pivotal role in fibrogenesis [21]. The most common examples of fibrosis are mesenteric fibrosis, associated with small bowel NENs in up to 50\% of cases [22], and carcinoid heart disease, characterized by development of fibrotic endocardial plaques, that affects up to $40 \%$ of patients with carcinoid syndrome [23, 24]. Several factors take part in NEN-related fibrogenesis, such as serotonin, connective tissue growth factor, PDGF, insulin-like growth factors (IGFs), FGF and VEGF [21]. A strict interaction between NEN cells and fibroblasts, with a mutual induction of cell proliferation, is relevant for these events [4].

The TME exerts a significant role in every step of tumorigenesis and progression through reciprocal interactions and modulation of chronic inflammation [25]. It is well-known the dual role of immune infiltration in tumors [26]. An imbalance of the immune system may cause chronic inflammation with a pro-oncogenic environment, on the contrary a well-regulated adaptive immune response is considered anti-tumorigenic [27]. Immune surveillance can eliminate some pre-malignant lesions [28], but over time, tumor cells can undergo a process called immune editing [29], becoming resistant to the first line of defense and able to manipulate immune cells through secretion of chemokine and cytokines [26]. Therefore, an inflammatory response may be either pro- or antitumorigenic, depending on the overall balance of inflammatory mediators and on the type of immune cells infiltrating the tumor. These aspects have been also reported in GEP-NENs, where chronic inflammation is a relevant hallmark [1].

Tumor-infiltrating immune cells include $\mathrm{T}$ and $\mathrm{B}$ lymphocytes, natural killer (NK) cells, macrophages, dendritic cells (DC) and neutrophils $[30,31]$. In a contest of chronic inflammation, leukocytes provide directly and indirectly several factors that can promote proliferation of cancer and stromal cells [32], stimulate angiogenesis, facilitate cancer cell dissemination and tumor immune evasion [33].

Tumor-infiltrating lymphocytes contain various proportions of T helper cells (CD4+) and cytotoxic $\mathrm{T}$ cells $(\mathrm{CD} 8+)$. Their presence is associated with a better prognosis in a wide range of solid tumors $[25,30,34]$. In NENs, particularly in carcinoids of lung and midgut, tumor-infiltrating lymphocytes (CD4+, CD8+ and CD20+) are often found and its occurrence correlates inversely with the presence of metastases [35]. Also pancreatic NENs commonly showed an intratumoral infiltration with CD4+, CD8+ and CD3+ T cells [36]. A recent paper characterized T-cell subpopulations in both intra- and extra-tumoral compartments in small intestine and pancreatic NENs through a panel of Tcell markers, comprising CD3 (general T-cell marker), CD45RO (T memory), CD8 (cytotoxic T 
cell), and FOXP3 (T regulatory cell). T-cells (CD3+, CD45RO+ and CD8+) were observed in both small intestine and pancreatic NENs, with a more relevant infiltration in pancreatic NENs, particularly in the extratumoral compartment. Levels of FOXP3 T regulatory cell infiltration were low in both tumors [37]. However, the expression of regulatory $\mathrm{T}$ cells appears to be not marginal in NENs, particularly in aggressive forms. These cells can stimulate metastasis formation and mediate the suppression of the immune system [38-40]. In another series of NENs, pancreatic intratumoral regulatory $\mathrm{T}$ cell infiltration was present in $55 \%$ of intermediate/high-grade tumors, whereas only in $16 \%$ of low-grade NENs [39]. Patients with midgut carcinoid showed higher levels of circulating regulatory $\mathrm{T}$ cells compared to healthy donors, particularly in patients with a high tumor burden [40].

Macrophages represent a remarkable portion in tumor mass. These cells display a substantial grade of plasticity, with different state of activation in response to a variety of external stimuli. Indeed, macrophages can be polarized into type I (M1) and type II (M2) [41]. M1 macrophages exert an anti-tumor effect, through the production of several pro-inflammatory cytokines, chemokines, and effector molecules, such as interleukin-1 (IL-1), IL-12, IL-23, TNF- $\alpha$, CXCL10, iNOS and MHCI/II. In contrast, M2 macrophages promote tumor proliferation and progression, tumor angiogenesis, metastasis formation and immune suppression, through the expression of a wide spectrum of anti-inflammatory molecules, such as IL-10, TGF- $\beta$ and arginase-1 [41, 42]. M2 macrophages can also switch T-lymphocytes to regulatory $\mathrm{T}$ cells, allowing the suppression of tumor immunity [43]. Numerous studies have demonstrated in most human cancers that a high presence of infiltrated macrophages is linked with poor prognosis [26, 44]. In pancreatic NENs, tumor-associated macrophages infiltration correlates with proliferative activity, tumor grade, presence of liver metastases, angiogenesis and recurrence after surgery [45-47]. In addition, low tumor-associated macrophages, low peritumoral CD4+ cell and high intratumoral CD8+ T cell infiltration was associated with prolonged disease-free and/or disease-specific survival in pancreatic NENs [48].

DCs are key mediators of the adaptive and innate immune responses, therefore, these cells play a pivotal role in shaping the immune response. DCs are designed to present antigens and provide different signals, such as co-stimulatory molecules and cytokines, essential for $\mathrm{T}$ cell activation, to interact with other immune cells, including NK and B cells [49]. Tumor-infiltrating DCs are present in different types of solid tumors and can be associated with both a better and poor prognosis [50]. Besides, phenotype and amount of DCs are dynamic over time and may considerably influence tumor progression [49]. Although a complete characterization of DCs has never been reported in GEP NENs, Schott et al. described that vaccination with tumor lysate-pulsed DCs induced a clear 
antitumor effect in a patient with pancreatic neuroendocrine carcinoma [51]. Interestingly, Papewalis and colleagues identified a population of DCs with NK cell properties, expressing the CD56 NK marker [52]. Afterwards, it has been reported higher numbers of circulating CD14+/CD56+ monocytes in 4 patients with gastrointestinal neuroendocrine cancer compared to healthy controls [53].

NK cells are a subset of innate lymphoid cells and represent about 5-15\% of the circulating blood mononuclear cell population. These cells are involved in the first line of defense against infection and cancer [54, 55]. It has been reported that NK cell activity, expressed as percentage of cytotoxicity in patients with gastrointestinal NENs, is affected by the type of gastrointestinal hormones produced and by the course of the disease with an impairment during tumor progression [56]. In addition, serotonin, the hormone most frequently related to carcinoid syndrome in NENs, stimulates migration of NK cell [57] and protects these cells against oxidatively induced functional inhibition and apoptosis [58].

\subsection{Inflammatory mediators}

The interplay between immune cell components and tumor cells is well orchestrated and several molecular mediators and pathways take part in inflammation-mediated cancer and immune modulation. Common inflammatory mediators are cytokines, chemokines, nuclear factor kappa B (NFk-B), STAT3, cyclooxygenase-2 and reactive oxygen and nitrogen species. An inflammatory stimulus causes the recruitment and activation of different immune cells (macrophages, DCs and neutrophils), which release reactive oxygen and nitrogen species. The over-production of these oxidative agents causes genomic instability, the increase of angiogenesis and transcriptional activation of proto-oncogenes, concurring to inflammation-induced carcinogenesis and tumor metastatic potential [59].

Chronic inflammation plays a critical role in the occurrence of GEP NENs through the network of different cytokines and growth factors, which modulate tumor cell growth [60], such as TNF- $\alpha$, IL2, IL-6, IL-8, IL-1 $\beta$ [61-65]. Noteworthy, cytokine genes are highly polymorphic. Single nucleotide polymorphisms affect cytokine expression and function regulation. $I L-2-330 G / G$ genotype was associated to higher IL-2 serum levels and an higher risk to develop GEP NENs compared to healthy volunteers. Interestingly, highest IL-2 serum levels were observed in patients with functional NENs [61]. Similar associations have been observed between $I L-6-174 G / G$, $T N F-\alpha$ $1031 C$ and $I L-1 \beta-511 C / T$ genotypes, high circulating levels of corresponding cytokines and an increased risk to develop GEP NENs [62, 66, 67]. GEP NENs are characterized by an abundant production and secretion of growth factors, in particular VEGF, EGF, PDGF, IGF, FGF and TGF- $\beta$, 
which, in combination with high level of cytokines, connect chronic inflammation to gastrointestinal carcinogenesis [68-71].

The pro-inflammatory mediators, produced during chronic inflammation, activate several signaling cascades, such as NFk-B and STAT3 pathways, that are central in the development and maintaining of the TME. NFk-B is a transcription factor that, following an inflammatory stimulus, translocates to the nucleus, where it activates transcription of target genes encoding pro-inflammatory cytokines, chemokines, NOS2 and cyclooxygenase-2. Moreover, NFk-B activation stimulates angiogenesis by VEGF secretion and makes tumor cells more resistant to necrosis and apoptosis. NFk-B is linked to different cellular signaling pathways. Over the last years, several reports have described NotchNFk-B pathway crosstalk [72]. In NENs it has been demonstrated that non-canonical Notch signaling impacts on tumorigenesis by the involvement of different signaling pathways, among them NFk-B [72, 73].

The signal transducer and activator of transcription, STAT3, has a relevant role in inducing and maintaining a pro-carcinogenic inflammatory TME. Its persistent activation in cancer cells promotes cell proliferation, tumor invasion and angiogenesis. Like NFk-B, STAT3 is activated by different factors and it can stimulate the transcription of several pro-inflammatory cytokines, controlling inflammation and immune evasion. In GEP NENs STAT3 has been reported to be upregulated and nuclear STAT3 expression correlated with metastatic status [74].

Other players taking part in this complex scenario, are cyclooxygenases. These are enzymes necessary to the production of prostaglandins from fatty acids. Prostaglandins are key mediators in inflammation, and in tumors can affect cell proliferation, DNA mutation rates, angiogenesis and promote metastasis formation [75]. Cyclooxygenase-2 expression has been detected in the vast majority of GEP NENs, both in functioning and non-functioning tumors [76], and its expression has been associated with a poor prognosis and more aggressive pathologic variables [77-79].

Therefore, chronic inflammation promotes tumor, causing genomic instability, increasing angiogenesis, altering the genetic/epigenetic state and increasing cell proliferation. Several studies have shown that GEP NENs are closely associated with inflammatory conditions.

\section{NEN and inflammatory GEP diseases}

The gastrointestinal tract contains the highest concentration of bacteria anywhere within the human body. This organ is constantly exposed to materials originating from the external environment. The balance of the gastrointestinal microbial community is critical not only for this organ but also for 
maintenance of host health. Indeed, failure of gut homeostasis is an important factor in the pathogenesis and progression of systemic inflammation, which has a relevant role in the process of aging and several age-related disease [80, 81].

Throughout the whole gastroenteric tract and pancreas at least 19 types of neuroendocrine cells have been observed. As previously reported, these cells are not exempt from the detrimental effects of long-standing inflammation. Indeed, neuroendocrine cells can be overstimulated by chronic inflammation, leading to hyperplasia and sometimes to dysplasia, that may evolve to neoplastic transformation. This consequential relationship has been demonstrated in some districts of the GEP tract.

\subsection{Gastric NEN}

Gastric NENs are tumors originating from enterochromaffin-like (ECL) cells which are mainly localised in the gastric fundus and corpus. The main role of ECL-cells is the secretion of histamine, that stimulates acid secretion by parietal cells. Clinically, gastric NENs are categorized into types I, II, and III. Type I lesions correspond to the majority of gastric NENs and they are associated with chronic atrophic gastritis, either autoimmune-driven or as a consequence of Helicobacter pylori infection. In chronic atrophic gastritis, the destruction of the gastric parietal cells reduces the production of hydrochloric acid and intrinsic factor, promoting hypergastrinemia and pernicious anemia, respectively. The gastrin excess stimulates ECL cells proliferation and favors the development of type I gastric NEN $[82,83]$.

A population-based case-control study, comparing 1,138,390 cancer cases with 100,000 matched individuals without cancer, showed that subjects with chronic atrophic gastritis associated with pernicious anemia have a significantly increased risk of type I gastric NENs (odds ratio, 11.43; 95\% CI 8.90-14.69) [84]. This tumor arises in patients with chronic atrophic gastritis in a percentage variable from 1 to $11 \%$ [85-88].

Helicobacter pylori is a gram-negative bacterium whose outer membranes are composed by lipopolysaccharides. Experiments made on rat ECL cell preparation showed that Helicobacter pylori lipopolysaccharides stimulate histamine release, that was independent by the gastrin action, and potentiate gastrin-driven DNA synthesis in ECL cells [89].

Other alterations in the gastric microbiota could be also involved in this detrimental process. In fact, hypochlorhydria is able to modify the composition of the gastric microbiota by providing a different environment for colonization. This event could potentially increase the risk of developing a gastric malignancy. A recent study comparing the human gastric microbiota in different conditions, showed that autoimmune atrophic gastritis resulted in greater bacterial abundance and diversity compared to 
normal stomach and patients with Helicobacter pylori-induced atrophic gastritis. In both patients with atrophic gastritis due to autoimmune etiology or Helicobacter pylori, an over-activation of several pathways has been observed compared to controls. Interestingly, gastric-atrophy resulted to be associated with a modulation in the citric acid cycle, a biochemical pathway with a relevant role in gastric carcinogenesis [90].

Therefore, autoimmune stimuli or Helicobacter pylori infection trigger an inflammatory response that determines parietal cell loss [91]. ECL cells are spared by this cellular destruction and induced to proliferate [89]. Indeed, in the setting of type A chronic atrophic corpus-fundus restricted gastritis, both hyperplastic and dysplastic lesions of ECL cells may be observed (figure 2), each bearing increased risk of tumor development [88]. It was shown that a gastric mucosa with severe hyperplasia (at least 6 intraglandular ECL cell chains of at least 5 cells each per mm of mucosa or at least 9 linear plus micronodular changes) and dysplasia (enlarged, fused or stroma dissected micronodules or microinfiltrative lesions) needs to be adequately followed by endoscopy and biopsies because of the increased neoplastic risk of these lesions [88].

\subsection{Pancreatic NEN}

Chronic pancreatitis represents an independent significant risk factor for pancreatic cancer [92, 93]. The strength of the relationship between these two diseases has been widely reported. In a multicenter cohort study of 2015 cases [92] of pancreatitis, 56 cases of pancreatic cancer were registered during a mean follow-up of 7.4 years. Among these, 29 cases were diagnosed 2 years after the diagnosis of pancreatitis. This number was higher than the expected for age, sex and the center. A case-control study [93] analyzed how frequent was the occurrence of pancreatitis in 2639 patients with pancreatic cancer, compared to 7774 control subjects. The evidence was that pancreatitis was present in around $6 \%$ of patients with cancer and it represents a strong risk factor for development of pancreatic tumors. Although in most of these studies the tumor histotype was not specified, this association appears to be relevant for pancreatic adenocarcinoma.

On the other hand, it is less clear the potential association between NEN and pancreatitis. In this setting, even hyperplastic and dysplastic lesions of endocrine cells consequent to inflammation, have never been clearly described. Rather, what is known is that, in the late phase of chronic pancreatitis, an apparent prominence of the endocrine cells is observed, probably due to the preferential loss of acinar tissue. This "pseudohypertrophy" may be difficult to distinguish from neuroendocrine microadenoma (figure 3). Therefore, data related to the incidence of cancer in this setting may be influenced by the potential of incorrect diagnosis of NEN. 
A case-control study including 162 sporadic pancreatic NENs and 648 controls showed that history of chronic pancreatitis $(\mathrm{OR}=8.6 ; 95 \% \mathrm{CI}, 1.4-51)$ and diabetes $(\mathrm{OR}=40.1 ; 95 \% \mathrm{CI}, 4.8-328.9)$ resulted to be independent risk factors for the development of this tumor [94]. Although the association between pancreatic NENs and chronic pancreatitis has been not confirmed in other studies, a recent meta-analysis showed that history of diabetes mellitus was associated with an increased risk of sporadic pancreatic NENs (pooled adjusted odds ratio 2.74, 95\% CI: 1.63-4.62) [95]. It is still unclear whether diabetes is a real risk factor or a secondary effect due to the pancreatic tumor. Furthermore, it is possible that chronic inflammation and oxidative stress may contribute to the pathogenesis of both diabetes and pancreatic NENs through the induction of DNA mutation [96]. A recent study showed that in genetically engineered transgenic mice, chronic inflammation in the absence of TP53 developed in all animals several subtypes of pancreatic cancer, including NENs [97].

\subsection{Small bowel and appendix NEN}

Several chronic inflammatory bowel conditions represent a potential risk factor predisposing to the development of small bowel NENs [98].

In celiac disease (CD), an immune-mediated disorder involving the small bowel, serotoninproducing neuroendocrine cells are increased [99]. Well-oriented bioptic samples taken from 17 patients affected by refractory $\mathrm{CD}$, were compared with 84 non-healthy and 16 healthy control subjects. In this study the number of neuroendocrine cells was absolutely more represented in refractory $\mathrm{CD}$. A higher expression was also observed in case of $\mathrm{CD}$ before gluten-free diet that restored to normality after [99]. This finding was indicative of a possible etiologic role of the immune system in the proliferative activity of these cells [100]. In addition, significantly higher serotonin levels have been described in patients with CD compared to healthy subjects [101]. In a large population-based cohort study, the standardized incidence ratio for small-intestinal cancer (adenocarcinomas, stromal tumors and NENs) was more than fourfold in patients with CD. However, the association between CD and NENs is doubtful. Indeed, in this study there are no data

on the number of patients with NENs [102]. Despite the hyperplasia of entero-chromaffin cells has been demonstrated in $\mathrm{CD}$, only few case reports have been published describing $\mathrm{CD}$ subjects with small bowel NENs [103-107].

Population-based studies [108, 109] have shown that the incidence of NENs is significantly increased in inflammatory bowel diseases (IBD) involving the small bowel. Among a cohort of 20.917 patients affected by Crohn's disease in the time frame between 1978 and 2010, 23 small bowel adenocarcinoma and 9 NENs were observed, resulting, respectively in a 14-fold and 7-fold 
increased neoplastic risk, as compared to the general population. In both histotypes the severity of the surrounding inflammatory disease was moderate to severe and its distribution was extensive. Furthermore, while almost all adenocarcinomas arose in mucosal areas affected by Crohn's disease, $78 \%$ of NENs developed far from them. This suggests that the development of NENs may be secondary to the effects of pro-inflammatory cytokines, rather than a local inflammatory effect from adjacent Crohn's disease. In the same study 42.872 cases of ulcerative colitis were also analyzed and no significantly increased risk of cancer was found among those patients [108].

The appendix is the third more frequent site of gastrointestinal-NENs. Appendiceal NENs are often diagnosed incidentally on histopathological examination of appendectomy specimens. In about two thirds of cases, they are found at the tip of the organ and are not the direct cause of the appendicitis [110]. In case of acute appendicitis, the number of enterochromaffin cells, that populate the crypt epithelium, and of subepithelial neuroendocrine cells is depleted [111]. Although no clear data are available concerning a potential association between chronic appendiceal inflammation and risk of NEN, the inflammation caused by other disease, such as Crohn's disease, represents a favorable situation for the development of the appendiceal NEN. Indeed, it seems to occur more frequently in the samples from inflamed surrounding than that reported in autopsy studies [112].

A recent meta-analysis of observational studies provides additional evidence for a link between inflammation and intestinal NENs. This study reported that aspirin use was associated with a significant decrease in the risk of several tumors, including small intestinal NENs $(R R=0.17,95 \%$ CI: 0.05-0.58) [113].

\subsection{Colonic and rectal NEN}

During inflammatory diseases affecting the colonic and rectal tube, as IBD, post-dysenteric colitis, Campylobacter enteritis and irritable bowel syndrome, an increase in number of neuroendocrine cells (figure 4) can be observed [114]. In all these cases, there is a disruption of the intestinal epithelial barrier that dysregulates innate and immune responses toward the enteric microbiota. This favors the release of several cytokines, that finally affect the commitment of multipotentialsecretory precursor cells and promote the differentiation of enteroendocrine precursor cells [115]. This phenomenon was deepened with in vitro and in vivo models of intestinal inflammation [114], where it was shown that PI3K/Akt signaling and autophagy are implicated in the increase of colonic intestinal epithelial cells expressing chromogranin. Indeed, the concomitant treatment of interferon$\gamma$ plus TNF- $\alpha$ increased the number of chromogranin A-positive cells in the distal colon of colitic mice and this determined an increase of pAkt (Ser473) and pAkt(Thr308), an augmented 


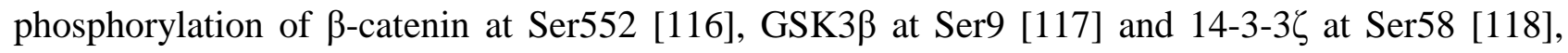
three well-known targets of Akt, and enhanced PTEN phosphorylation. p-PTEN is the inactive form, that causes PI3K/Akt signaling activation in chromogranin A-positive cells. The reason why cytosolic chromogranin A increases in case of inflammation is not clear. It was supposed that entero-endocrine cells, with their capacity of antigen internalization, could represent a relevant sensor for the mucosa during inflammation. Similarly, in humans neuroendocrine differentiation is relatively common and represents an early event in the ulcerative-colitis-associated carcinogenesis, where chromogranin A and p53 are up-regulated [119].

Discordant opinions exist on whether the coexistence of IBD (both ulcerative colitis and Crohn's disease) and colonic and rectal NEN is only coincidental. According to some authors [120], an apparent high rate of incidental NENs in IBD patients could be explained only because they frequently undergo intestinal surgery. Indeed, adjusted for resection type, sex and age, a lower prevalence of NENs in IBD patients has been reported compared to non-IBD patients (diverticulitis or ischemic).

Other studies reported an increased risk (up to 15 times) of intestinal NENs in IBD. While neuroendocrine tumors are more common in segments that are free from inflammation [121, 122], neuroendocrine carcinomas develop mainly in inflamed mucosa [122, 123], just like what it happens for non-neuroendocrine cancer. Although NENs occur in ulcerative colitis [124] as well as during Crohn's disease, some authors are inclined to think that the incidence is higher in Crohn's disease, triggered by prolonged inflammation, even in distant bowel segments [121, 125].

\section{Prognostic value of inflammatory markers in NENs}

In support of a role of inflammation in tumor development and progression, several studies recognized few inflammatory biomarkers as independent prognostic markers in patients with tumors [126]. Most of these data have been recently confirmed in NENs. Neutrophils, the most abundant white blood cell subset, appear to have an active role in tumorigenesis and tumor progression by secreting several cytokines, able to promote tumor cell proliferation, local invasion, angiogenesis and resistance to chemotherapy [127]. On the other hand lymphocytes play an important role in cell-mediated immune response activation. CD4+ T lymphocytes are involved in senescence and cancer immune-surveillance, detecting and eradicating precancerous and cancerous cells, also by activation of CD8+ T lymphocytes. Lymphocyte infiltration is common in NENs, as assessed by immunohistochemistry for CD3, CD4, CD8, and CD56 [39, 128]. In patients with 
intermediate-grade NENs a prominent tumor infiltration of $\mathrm{T}$ cells (CD3+) was associated with improved regression free survival, while a low level of infiltrating regulatory $\mathrm{T}$ cells in liver metastases was a predictor of prolonged survival [39].

Neutrophil-to-lymphocyte ratio (NLR) and platelet-to-lymphocyte ratio (PLR) are systemic inflammation markers with a prognostic value in several neoplasms. Some studies addressed the prognostic relevance of NLR and PLR in GEP NENs, demonstrating that these parameters could be useful in identifying patients with a worse outcome $[129,130]$. In a retrospective study including 172 patients with pancreatic NENs, elevated NLR and PLR were both associated with advanced tumor stage and high grade. In the univariate analysis, elevated NLR and PLR were both significantly associated with decreased overall survival and disease free survival, while in the multivariate analysis, the preoperative NLR, but not the PLR, was an independent risk factor. In detail, a preoperative NLR > 2.31 was predictive of significantly worse survival in the subgroup of patients with stage I/II or grade 1/2 tumors. Moreover, predictive models based on both the NLR and conventional stratification systems, such as the WHO classification and AJCC stage, showed improved predictive power as compared to the stratification systems alone [131].

Recently, increased NLR was found to be associated to advanced T stage, lymph node metastasis, tumor thrombus formation and advanced grade in pancreatic NENs. In addition, the recurrence-free survival of these patients with high NLR was significantly lower compared with those with low NLR [132]. Accordingly, in patients with gastric NEN, NLR was an independent prognostic factor for recurrence-free survival and overall survival [133].

The gamma-glutamyltransferase (GGT) level is a biomarker of oxidative stress and correlates with inflammation in the extracellular tissue microenvironment. GGT can play a relevant role in cancer progression and biological behaviour, and is considered a significant prognostic biomarker in several tumors. On the other hand, lymphocytopenia, indicating a state of depressed immune function, could negatively affect survival of cancer patients because of a reduced host response. Therefore, the GGT to lymphocyte ratio index (GLRI) could represent a potentially useful prognostic biomarker in oncology. In a retrospective study including 125 non-functioning pancreatic NENs undergoing curative resection, GLRI was found to be an independent predictor of overall survival and disease free survival. Moreover, preoperative GLRI was associated with advanced tumor stage [134].

$\mathrm{C}$ reactive protein $(\mathrm{CRP})$ is an acute-phase protein, produced in the liver, whose synthesis is triggered by secretion of IL-6 from macrophages and T cells. Any type of chronic or acute inflammatory process can activate acute phase response, making CRP levels a sensitive but unspecific marker. CRP has been shown to be an independent prognostic marker in patients with 
secreting (insulinoma, gastrinoma and other rare functioning tumours) and non-secreting sporadic pancreatic NENs, since it correlated with overall survival. Moreover in univariate Cox regression, pancreatic NEN patients with elevated CRP levels had a significantly higher hazard ratio for death [135].

Angiopoietins (Ang)-1 and -2, and the tyrosine kinase receptor Tie-2 family are involved in angiogenesis that in turn is known to have a key function in tumorigenesis. In addition, this system has a relevant role in the inflammatory processes, with a close loop relationship between angiogenesis and inflammation, particularly in IBD. Interaction of Ang-1 with Tie-2 promotes endothelial cell survival, while Ang-2 exerts a marked pro-angiogenic effect, when VEGF is present, and is involved in chemo-attraction of monocytes in neoplastic tissue. Monocytes expressing Tie-2 and recruited into inflamed or neoplastic tissues can promote angiogenesis. Moreover, there is a soluble form of Tie-2 that has been found increased in several conditions including cancer. GEP NEN patients showed enhanced serum levels of soluble form of Tie-2, Ang1, and Ang-2, compared to age-matched healthy controls. Soluble Tie-2 and Ang-2 levels were significantly higher in GEP NENs with metastases compared to those without metastases. Furthermore, Ang-1, Ang-2, and Tie-2 expression was found to be increased in freshly isolated tumor cells from GEP NEN. Interestingly, an enhanced expression and function of Tie-2 was detected in monocytes from GEP NEN patients. Overall these data would suggest that the Ang/Tie2 system is involved in the growth and dissemination of GEP NENs, also favouring the recruitment of Tie-2(+) monocytes to the tumor site, where they can promote inflammation and angiogenesis [136]. Similarly, Srirajaskanthan R et al. found Ang-2 levels to be increased in patients with well or moderately differentiated NENs, mostly of pancreatic, duodenal or jejunum origin, as compared to healthy controls, and to be significantly higher in presence of metastases as compared to nondisseminated tumours. Moreover patients with higher Ang-2 levels ( $>4756 \mathrm{pg} / \mathrm{ml})$ showed a shorter time to disease progression, overall suggesting a potential prognostic role for Ang-2 in patients with NENs [137].

\section{Therapeutic applications with new checkpoint inhibitors}

Unravelling and understanding the mechanisms implicated in the immune response to neoplasms, induced by tumour-associated antigens, is crucial also in the context of NENs, for gaining new knowledge on tumour biology and for improving the management with the perspective of an immunotherapeutic approach. The therapeutic implications of the involvement of immune system in patients with NENs are known since the introduction of interferon- $\alpha$ biotherapy, which inhibits cell 
cycle progression and hormone synthesis in tumor cells, reduces neoangiogenesis, and activates immune cells [138]. Somatostatin receptors, which are targets widely used for the diagnosis and therapy of NETs [139-142], are also present in immune cells and able to mediate immune and inflammatory reactions [143]. Monocyte-derived cells and mature T-lymphocytes express somatostatin receptors -2 and -3 , respectively. Human lymphoid follicle centers, thymus, and spleen express both receptors as well. In thymus, several evidences suggest the potential physiological role of somatostatin receptors in thymocytes maturation [144]. Although the effects of somatostatin analogues on immune system are not well defined in patients with NETs, these compounds are able to potentiate the cytotoxicity of interleukin- 2 activated peripheral blood mononuclear cells in patients with medullary thyroid cancer [145].

The occurrence of immune response to NENs is demonstrated by the frequent finding of lymphocyte infiltration within the tumour, as discussed in the previous paragraphs. In the view of a potential immunotherapy, specific tumour-associated antigens recognised by CD8+ $\mathrm{T}$ cells have been identified in patients with midgut NENs [128].

NENs can elude immunosurveillance regardless of the immunocompetence of the host. In pancreatic NENs, HLA class I antigen expression was lost or reduced in most of the cases, with the loss of beta-2microglobulin as the most frequent alteration in HLA class I phenotype. HLA class II antigens seemed not to contribute to the biology of NENs, since they were not expressed in all investigated samples [36]. However, in another study, MHC class II expression on pancreatic tumor cells correlated significantly with severity and activity of intratumoral inflammation, as well as with the infiltration of CD4+ T lymphocytes [146].

Anti-tumor immune responses can be impaired by regulatory $\mathrm{T}$ cells. Midgut carcinoid patients exhibited increased frequencies of circulating regulatory $\mathrm{T}$ cells and patients' $\mathrm{T}$ cells were less responsive to polyclonal activation and had a decreased proliferative capacity compared to controls. Moreover, circulating T helper-promoting cytokines were reduced [40].

Programmed death 1 (PD-1), its ligands (PD-L1 and PD-L2) and cytotoxic T-lymphocyte antigen 4 (CTLA-4) are immunosuppressive molecules with a relevant role in the host immune response to tumors, inhibiting T-cell activation. Lamarca A. et al. found that one third of 62 patients with welldifferentiated small intestinal NEN expressed PD-L1 in tumor or tumor-infiltrating lymphocytes [147]. Expression of PD-L1 was observed also in $14 \%$ of tumors and in $27 \%$ of tumor-associated immune cells in patients with poorly-differentiated neuroendocrine carcinomas of the digestive system [148]. In GEP NEN patients, PD-L1 expression was found significantly associated with a high-grade WHO classification (G3) but not with gender, primary site, or lymph node status. Moreover, G3 tumors were characterized by strong PD-L1 expression in intra/peri-tumoral 
infiltrating immune cells [149]. Likewise, in a study of 32 metastatic GEP NEN, the expression of PD-L1, observed in $22 \%$ of patients, was associated with higher WHO tumor grade (grade 3 ) and had both predictive and prognostic value for survival of patients [150]. In 244 GEP NENs, mostly of the small intestine and pancreas and predominantly G1-G2, high tumor-infiltrating lymphocytes (19.6\%) and high PD-1 (16.1\%) expression significantly correlated with shorter patient survival and with a higher grading. In the same study, expression of PD-L1 (8.7\%) showed a trend toward a shorter patient survival [151]. Furthermore, Sampedro Nunez et al. found PD-1/PD-L1 expressed in 1 to $8 \%$ of GEP NENs. In the same patients, PD-1 tumor expression was higher in metastatic patients, while PD-1 expression in peripheral blood monocytes was associated with tumor progression [152].

Conversely, in 66 patients with GEP NEN, mostly of pancreatic origin, PD-L1 expression was observed in 9\%, while PD-L2 was present in 50\% with no association with disease stage at diagnosis or survival. However, they found an inverse relationship between hypoxia and angiogenesis biomarkers and PD ligands, as PD-L1 positive tumors had lower VEGF-A, Hif-1a and Carbonic Anhydrase (CaIX) expression, while PD-L2 positive tumours had lower CaIX and lower proportion of vascular invasion [153]. Recently, in 102 NENs of duodenum, jejunum and ileum, expression of PD-L1 in $\geq 1 \%$ and $\geq 50 \%$ of tumor cells was found in $39 \%$ and $14 \%$ of cases respectively, with an intratumor host immune response found to be apparently absent in $34 \%$ and intense in $21 \%$ of cases. PD-L1 expression and extent of immune infiltration were significantly higher in duodenal as compared with jejunal/ileal NENs. However, neither PD-L1 expression nor the degree of immune infiltration showed any prognostic significance [154].

Antibodies targeting PD-1 (pembrolizumab, nivolumab, PDR001, JS001), PD-L1 (avelumab, durvalumab) or CTLA-4 (ipilimumab, tremelimumab) have been recently used in several cancers with promising results, and few trials are now in progress for GEP NENs (table 1). In a phase Ib study (KEYNOTE-028), that included patients with various advanced solid tumors, pembrolizumab (10 mg/kg every 2 weeks) resulted in an objective response rate of $12 \%$ out of 25 advanced PD-L1positive carcinoid patients and $6 \%$ out of 16 pancreatic NEN patients. None of the carcinoid and pancreatic NEN patients reached complete remission, whereas $60 \%$ and $88 \%$ of the patients, respectively, had stable disease [155].

Taking into consideration that, in some studies, PD-1/PD-L1 expression appears to correlate with higher NEN grade and with reduced survival, immunotherapy targeting this system might be interesting for this subgroup of tumors with a poor prognosis. Nevertheless, more knowledge about the composite immune landscape of these heterogeneous tumors needs to be gained in order to identify the subset of NEN patients most likely to benefit from immunotherapeutic approach. 


\section{Conclusions}

Several evidences suggest a relationship between neuroendocrine system and inflammation, which in turn can play a relevant role in tumorigenesis. Inflammatory mediators, which are produced by the NEN or as part of the host innate immune response, can favour angiogenesis, cancer progression and metastatic spread, and can promote immune editing. On the other hand, a balanced immune system represents a relevant step in cancer prevention through the elimination of dysplastic and cancer cells. Therefore, an inflammatory response may be both pro- and anti-tumorigenic.

Although several studies reported an increased risk of GEP NENs in patients with gastrointestinal inflammatory diseases (chronic atrophic gastritis, chronic pancreatitis, celiac disease, Crohn's disease and ulcerative colitis), most of these studies are retrospective and characterized by potential biases. Therefore, further studies are required to improve the level of evidence, particularly concerning the association between NENs and IBD.

The modulation of the TME may represent an innovative therapeutic strategy in G3 NENs, through the use of checkpoint inhibitors binding to PD-1, PD-L1 or CTLA-4, thereby preventing tumors to evade the immune system. This aspect will be further defined with the completion of several ongoing clinical trials. 


\section{Acknowledgements}

This review is part of the 'Neuroendocrine Tumors Innovation Knowledge and Education' project led by Prof. Annamaria Colao and Prof. Antongiulio Faggiano, which aims at increasing the knowledge on NET.

We would like to acknowledge all the Collaborators of the "NIKE" project: Albertelli M., Altieri B., Ambrosetti E., Bianchi A., Bottiglieri L., Campione S., De Cicco F., Di Dato C., Di Molfetta S., Fanciulli G., Gallo M., Giannetta E., Grillo F., Grossrubatscher E., Guarnotta V., Lo Calzo F., Malandrino P., Martini C., Messina E., Modica R., Muscogiuri G., Pizza G., Razzore P., Rizza L., Rubino M., Ruggeri R., Sciammarella C., Zatelli M.C.

\section{Conflict of interest statement}

A. Colao and A. Faggiano has received consultant fees from Novartis and Ipsen. G. Vitale has received consultant fees from Novartis.

\section{Funding source}

This work was supported by the Italian Ministry of Education, University and Research (MIUR): PRIN 2017Z3N3YC. 
Figure legends:

Figure 1: Components of tumor microenvironment and their role in carcinogenesis and tumor progression through modulation of inflammation.

Figure 2: Gastric hyperplastic changes of ECL cells. (a) A mild atrophic gastritis is shown (hematoxylin and eosin stain, 10x magnification). (b) At higher magnification (hematoxylin and eosin stain, 20x magnification), few cells with a clear perinuclear halo can be observed (arrows). (c) They are more evident on immunohistochemistry with chromogranin (20x magnification): neuroendocrine cells display both linear (arrow) and micronodular arrangement $(*)$.

Figure 3: Pseudohypertophy of neuroendocrine cells in chronic pancreatitis. (a) An example of chronic pancreatitis, where exocrine pancreatic tissue is partially replaced by fibrosis (hematoxylin and eosin stain, 20x magnification). (b) Langerhans islands seem to be hyperplastic and more evident on immunohistochemistry with chromogranin (20x magnification).

Figure 4: Inflammatory bowel diseases and NEN. (a) The rectal submucosa was occupied by a neuroendocrine carcinoma (positive to chromogranin) in a patient with a history of ulcerative colitis of at least 20 years. In the mucosa overlying the neoplastic lesion, neuroendocrine cells were normally represented (20x magnification). (b) Far from this lesion, an increased number of neuroendocrine cells was detected (40 x magnification). 


\section{References}

[1] Walenkamp A, Crespo G, Fierro Maya F, Fossmark R, Igaz P, Rinke A, et al. Hallmarks of gastrointestinal neuroendocrine tumours: implications for treatment. Endocrine-related cancer. 2014;21:R44560.10.1530/ERC-14-0106

[2] Giannetta E, Guarnotta V, Rota F, de Cicco F, Grillo F, Colao A, et al. A rare rarity: Neuroendocrine tumor of the esophagus. Critical reviews in oncology/hematology. 2019;137:92107.10.1016/j.critrevonc.2019.02.012

[3] Wang M, Zhao J, Zhang L, Wei F, Lian Y, Wu Y, et al. Role of tumor microenvironment in tumorigenesis. Journal of Cancer. 2017;8:761-73.10.7150/jca.17648

[4] Cuny T, de Herder W, Barlier A, Hofland L. Role of the tumor microenvironment in digestive neuroendocrine tumors. Endocrine-related cancer. 2018;25:R519-R44.10.1530/ERC-18-0025

[5] Zhang WH, Wang WQ, Gao HL, Yu XJ, Liu L. The tumor immune microenvironment in gastroenteropancreatic neuroendocrine neoplasms. Biochimica et biophysica acta Reviews on cancer. 2019;1872:188311.10.1016/j.bbcan.2019.188311

[6] Carmeliet P, Jain RK. Angiogenesis in cancer and other diseases. Nature. 2000;407:24957.10.1038/35025220

[7] La Rosa S, Uccella S, Finzi G, Albarello L, Sessa F, Capella C. Localization of vascular endothelial growth factor and its receptors in digestive endocrine tumors: correlation with microvessel density and clinicopathologic features. Human pathology. 2003;34:18-27.10.1053/hupa.2003.56

[8] Angelescu R, Burada F, Angelescu C, Gheonea DI, lordache S, Mixich F, et al. Expression of vascular endothelial growth factor and epidermal growth factor receptor in pancreatic ductal adenocarcinomas, neuroendocrine tumours and chronic pancreatitis. Endoscopic ultrasound. 2013;2:86-91.10.4103/23039027.117692

[9] Cigrovski Berkovic M, Cacev T, Catela Ivkovic T, Marout J, Ulamec M, Zjacic-Rotkvic V, et al. High VEGF serum values are associated with locoregional spread of gastroenteropancreatic neuroendocrine tumors (GEP-NETs). Molecular and cellular endocrinology. 2016;425:61-8.10.1016/j.mce.2016.01.013

[10] Inoue M, Hager JH, Ferrara N, Gerber HP, Hanahan D. VEGF-A has a critical, nonredundant role in angiogenic switching and pancreatic beta cell carcinogenesis. Cancer cell. 2002;1:193-202.10.1016/S15356108(02)00031-4

[11] Lawson ND, Weinstein BM. In vivo imaging of embryonic vascular development using transgenic zebrafish. Developmental biology. 2002;248:307-18.10.1006/dbio.2002.0711

[12] Gaudenzi G, Albertelli M, Dicitore A, Wurth R, Gatto F, Barbieri F, et al. Patient-derived xenograft in zebrafish embryos: a new platform for translational research in neuroendocrine tumors. Endocrine. 2017;57:214-9.10.1007/s12020-016-1048-9

[13] Gaudenzi G, Vitale G. Transplantable zebrafish models of neuroendocrine tumors. Annales d'endocrinologie. 2019;80:149-52.10.1016/j.ando.2019.04.013

[14] Vitale G, Gaudenzi G, Dicitore A, Cotelli F, Ferone D, Persani L. Zebrafish as an innovative model for neuroendocrine tumors. Endocrine-related cancer. 2014;21:R67-83.10.1530/ERC-13-0388

[15] Lu P, Takai K, Weaver VM, Werb Z. Extracellular matrix degradation and remodeling in development and disease. Cold Spring Harbor perspectives in biology. 2011;3.10.1101/cshperspect.a005058

[16] Garcia-Suarez O, Garcia B, Fernandez-Vega I, Astudillo A, Quiros LM. Neuroendocrine tumors show altered expression of chondroitin sulfate, glypican 1, glypican 5, and syndecan 2 depending on their differentiation grade. Frontiers in oncology. 2014;4:15.10.3389/fonc.2014.00015

[17] Garcia B, Garcia-Suarez O, Fernandez-Vega I, Vallina A, Astudillo A, Quiros LM. Heparanase and heparanase 2 display differently deregulation in neuroendocrine tumors, depending on their differentiation grade. Histology and histopathology. 2016;31:73-81.10.14670/HH-11-650

[18] Arcucci A, Ruocco MR, Granato G, Sacco AM, Montagnani S. Cancer: An Oxidative Crosstalk between Solid Tumor Cells and Cancer Associated Fibroblasts. Biomed Res Int. 2016;2016:4502846.10.1155/2016/4502846

[19] Avagliano A, Granato G, Ruocco MR, Romano V, Belviso I, Carfora A, et al. Metabolic Reprogramming of Cancer Associated Fibroblasts: The Slavery of Stromal Fibroblasts. Biomed Res Int. 2018;2018:6075403.10.1155/2018/6075403 
[20] Dimmeler S, Zeiher AM. Netting Insights into Fibrosis. New Engl J Med. 2017;376:14757.10.1056/Nejmcibr1616598

[21] Laskaratos FM, Rombouts K, Caplin M, Toumpanakis C, Thirlwell C, Mandair D. Neuroendocrine tumors and fibrosis: An unsolved mystery? Cancer. 2017;123:4770-90.10.1002/cncr.31079

[22] Daskalakis K, Karakatsanis A, Stalberg P, Norlen O, Hellman P. Clinical signs of fibrosis in small intestinal neuroendocrine tumours. The British journal of surgery. 2017;104:69-75.10.1002/bjs.10333

[23] Gustafsson BI, Hauso O, Drozdov I, Kidd M, Modlin IM. Carcinoid heart disease. International journal of cardiology. 2008;129:318-24.10.1016/j.ijcard.2008.02.019

[24] van der Horst-Schrivers AN, Wymenga AN, Links TP, Willemse PH, Kema IP, de Vries EG. Complications of midgut carcinoid tumors and carcinoid syndrome. Neuroendocrinology. 2004;80 Suppl 1:2832.10.1159/000080737

[25] Qu X, Tang Y, Hua S. Immunological Approaches Towards Cancer and Inflammation: A Cross Talk. Frontiers in immunology. 2018;9:563.10.3389/fimmu.2018.00563

[26] Mantovani A, Romero P, Palucka AK, Marincola FM. Tumour immunity: effector response to tumour and role of the microenvironment. Lancet. 2008;371:771-83.10.1016/S0140-6736(08)60241-X

[27] Schetter AJ, Heegaard NH, Harris CC. Inflammation and cancer: interweaving microRNA, free radical, cytokine and p53 pathways. Carcinogenesis. 2010;31:37-49.10.1093/carcin/bgp272

[28] Shankaran V, Ikeda H, Bruce AT, White JM, Swanson PE, Old LJ, et al. IFNgamma and lymphocytes prevent primary tumour development and shape tumour immunogenicity. Nature. 2001;410:110711.10.1038/35074122

[29] Finn OJ. Immuno-oncology: understanding the function and dysfunction of the immune system in cancer. Annals of oncology : official journal of the European Society for Medical Oncology. 2012;23 Suppl 8:viii6-9.10.1093/annonc/mds256

[30] Whiteside TL. The tumor microenvironment and its role in promoting tumor growth. Oncogene. 2008;27:5904-12.10.1038/onc.2008.271

[31] Coussens LM, Werb Z. Inflammation and cancer. Nature. 2002;420:860-7.10.1038/nature01322

[32] Balkwill F, Charles KA, Mantovani A. Smoldering and polarized inflammation in the initiation and promotion of malignant disease. Cancer cell. 2005;7:211-7.10.1016/j.ccr.2005.02.013

[33] Hanahan D, Coussens LM. Accessories to the crime: functions of cells recruited to the tumor microenvironment. Cancer cell. 2012;21:309-22.10.1016/j.ccr.2012.02.022

[34] Katz SC PV, Bamboat ZM, Shia J, Hedvat C, Gonen M et al. T cell infiltrate predicts longterm survival following resection of colorectal cancer liver metastases. Ann Surg Oncol 2009;16:2524-30.

[35] Roncati L, Manenti, A., Pusiol, T., Piscioli, F., Barbolini, G. The lymphocytic inflammation correlates with metastatic risk in carcinoid tumours. Inflamm Cell Signal. 2015;2:1-5.10.14800/ics.1049

[36] Ryschich E, Autschbach, F., Eisold, S., Klar, E., Buchler, M.W., Schmidt, J. Expression of HLA class I/II antigens and $\mathrm{T}$ cell immune response in human neuroendocrine tumours of the pancreas. Tissue Antigens. 2003;62:48-54.10.1034/j.1399-0039.2003.00075.x

[37] da Silva A, Bowden M, Zhang S, Masugi Y, Thorner AR, Herbert ZT, et al. Characterization of the Neuroendocrine Tumor Immune Microenvironment. Pancreas. 2018;47:11239.10.1097/MPA.0000000000001150

[38] Wang Y, Ma Y, Fang Y, Wu S, Liu L, Fu D, et al. Regulatory T cell: a protection for tumour cells. Journal of cellular and molecular medicine. 2012;16:425-36.10.1111/j.1582-4934.2011.01437.x

[39] Katz SC, Donkor C, Glasgow K, Pillarisetty VG, Gonen M, Espat NJ, et al. T cell infiltrate and outcome following resection of intermediate-grade primary neuroendocrine tumours and liver metastases. HPB : the official journal of the International Hepato Pancreato Biliary Association. 2010;12:674-83.10.1111/j.14772574.2010.00231.x

[40] Vikman S, Sommaggio R, De La Torre M, Oberg K, Essand M, Giandomenico V, et al. Midgut carcinoid patients display increased numbers of regulatory $T$ cells in peripheral blood with infiltration into tumor tissue. Acta Oncol. 2009;48:391-400.10.1080/02841860802438495

[41] Hao NB, Lu MH, Fan YH, Cao YL, Zhang ZR, Yang SM. Macrophages in tumor microenvironments and the progression of tumors. Clinical \& developmental immunology.

2012;2012:948098.10.1155/2012/948098 
[42] Schiavoni G, Gabriele L, Mattei F. The tumor microenvironment: a pitch for multiple players. Frontiers in oncology. 2013;3:90.10.3389/fonc.2013.00090

[43] Blaylock RL. Cancer microenvironment, inflammation and cancer stem cells: A hypothesis for a paradigm change and new targets in cancer control. Surgical neurology international. 2015;6:92.10.4103/2152-7806.157890

[44] Di Caro G, Cortese N, Castino GF, Grizzi F, Gavazzi F, Ridolfi C, et al. Dual prognostic significance of tumour-associated macrophages in human pancreatic adenocarcinoma treated or untreated with chemotherapy. Gut. 2016;65:1710-20.10.1136/gutjnl-2015-309193

[45] Pyonteck SM, Gadea BB, Wang HW, Gocheva V, Hunter KE, Tang LH, et al. Deficiency of the macrophage growth factor CSF-1 disrupts pancreatic neuroendocrine tumor development. Oncogene. 2012;31:1459-67.10.1038/onc.2011.337

[46] Wei IH, Harmon CM, Arcerito M, Cheng DF, Minter RM, Simeone DM. Tumor-associated macrophages are a useful biomarker to predict recurrence after surgical resection of nonfunctional pancreatic neuroendocrine tumors. Annals of surgery. 2014;260:1088-94.10.1097/SLA.0000000000000262

[47] Krug S, Abbassi R, Griesmann H, Sipos B, Wiese D, Rexin P, et al. Therapeutic targeting of tumorassociated macrophages in pancreatic neuroendocrine tumors. International journal of cancer. 2018;143:1806-16.10.1002/ijc.31562

[48] Cai L, Michelakos T, Deshpande V, Arora KS, Yamada T, Ting DT, et al. Role of Tumor-Associated Macrophages in the Clinical Course of Pancreatic Neuroendocrine Tumors (PanNETs). Clinical cancer research : an official journal of the American Association for Cancer Research. 2019;25:264455.10.1158/1078-0432.CCR-18-1401

[49] Tran Janco JM, Lamichhane P, Karyampudi L, Knutson KL. Tumor-infiltrating dendritic cells in cancer pathogenesis. Journal of immunology. 2015;194:2985-91.10.4049/jimmunol.1403134

[50] Karthaus N, Torensma R, Tel J. Deciphering the message broadcast by tumor-infiltrating dendritic cells. The American journal of pathology. 2012;181:733-42.10.1016/j.ajpath.2012.05.012

[51] Schott M, Feldkamp J, Lettmann M, Simon D, Scherbaum WA, Seissler J. Dendritic cell immunotherapy in a neuroendocrine pancreas carcinoma. Clinical endocrinology. 2001;55:271-7.10.1046/j.13652265.2001.01293.x

[52] Papewalis C, Jacobs B, Wuttke M, Ullrich E, Baehring T, Fenk R, et al. IFN-alpha skews monocytes into CD56+-expressing dendritic cells with potent functional activities in vitro and in vivo. Journal of immunology. 2008;180:1462-70.10.4049/jimmunol.180.3.1462

[53] Papewalis C, Jacobs B, Baran AM, Ehlers M, Stoecklein NH, Willenberg HS, et al. Increased numbers of tumor-lysing monocytes in cancer patients. Molecular and cellular endocrinology. 2011;337:5261.10.1016/j.mce.2011.01.020

[54] Fang F, Xiao W, Tian Z. NK cell-based immunotherapy for cancer. Seminars in immunology. 2017;31:3754.10.1016/j.smim.2017.07.009

[55] Lopez-Soto A, Gonzalez S, Smyth MJ, Galluzzi L. Control of Metastasis by NK Cells. Cancer cell. 2017;32:135-54.10.1016/j.ccell.2017.06.009

[56] Aparicio-Pages MN, Verspaget HW, Pena AS, Lamers CB. Natural killer cell activity in patients with adenocarcinoma in the upper gastrointestinal tract. Journal of clinical \& laboratory immunology. 1991;35:27-32

[57] Zimmer P, Bloch W, Kieven M, Lovenich L, Lehmann J, Holthaus M, et al. Serotonin Shapes the Migratory Potential of NK Cells - An in vitro Approach. International journal of sports medicine. 2017;38:857-63.10.1055/s-0043-113042

[58] Betten A, Dahlgren C, Hermodsson S, Hellstrand K. Serotonin protects NK cells against oxidatively induced functional inhibition and apoptosis. Journal of leukocyte biology. 2001;70:6572.10.1189/jlb.70.1.65

[59] Visconti R, Grieco D. New insights on oxidative stress in cancer. Current opinion in drug discovery \& development. 2009;12:240-5

[60] Cigrovski Berkovic M, Cacev T, Catela Ivkovic T, Zjacic-Rotkvic V, Kapitanovic S. New insights into the role of chronic inflammation and cytokines in the etiopathogenesis of gastroenteropancreatic neuroendocrine tumors. Neuroendocrinology. 2014;99:75-84.10.1159/000362339 
[61] Berkovic MC, Jokic, M., Marout, J., Radosevic, S., Zjacic-Rotkvic, V., Kapitanovic, S. IL-2 -330 T/G SNP and serum values - potential new tumour markers in neuroendocrine tumours of the gastrointestinal tract and pancreas (GEP-NETs). J Mol Med 2010;88:423-9.10.1007/s00109-009-0581-x. Epub 2010 Jan 5.

[62] Berkovic M, Cacev T, Zjacic-Rotkvic V, Kapitanovic S. TNF-alpha promoter single nucleotide polymorphisms in gastroenteropancreatic neuroendocrine tumors. Neuroendocrinology. 2006;84:34652.10.1159/000097988

[63] Pavel ME, Hassler G, Baum U, Hahn EG, Lohmann T, Schuppan D. Circulating levels of angiogenic cytokines can predict tumour progression and prognosis in neuroendocrine carcinomas. Clinical endocrinology. 2005;62:434-43.10.1111/j.1365-2265.2005.02238.x

[64] Maja Cigrovski Berković MJ, Jasminka Marout, Senka Radošević, Vanja Zjačić-Rotkvić, Sanja Kapitanović IL-6-174 C/G polymorphism in the gastroenteropancreatic neuroendocrine tumors (GEP-NETs). Experimental and Molecular Pathology. 2007;83:474-9

[65] Qian BF, El-Salhy M, Melgar S, Hammarstrom ML, Danielsson A. Neuroendocrine changes in colon of mice with a disrupted IL-2 gene. Clinical and experimental immunology. 2000;120:424-33

[66] Berkovic MC, Jokic M, Marout J, Radosevic S, Zjacic-Rotkvic V, Kapitanovic S. IL-6-174 C/G polymorphism in the gastroenteropancreatic neuroendocrine tumors (GEP-NETs). Exp Mol Pathol. 2007;83:474-9.10.1016/j.yexmp.2007.08.018

[67] Cigrovski Berkovic M, Catela Ivkovic T, Marout J, Zjacic-Rotkvic V, Kapitanovic S. Interleukin 1beta gene single-nucleotide polymorphisms and susceptibility to pancreatic neuroendocrine tumors. DNA and cell biology. 2012;31:531-6.10.1089/dna.2011.1317

[68] Delle Fave G, Corleto VD. Oncogenes, growth factors, receptor expression and proliferation markers in digestive neuroendocrine tumours. A critical reappraisal. Annals of oncology : official journal of the European Society for Medical Oncology. 2001;12 Suppl 2:S13-7.10.1093/annonc/12.suppl_2.s13

[69] Höpfner M, Schuppan, D., Scherübl, H. Treatment of gastrointestinal neuroendocrine tumors with inhibitors of growth factor receptors and their signaling pathways: Recent advances and future perspectives. World journal of gastroenterology. 2008;14:2461- 73. 10.3748/wjg.14.2461

[70] Wulbrand U, Wied, M., Zofel, P., Goke, B., Arnold, R., Fehmann, H.C. Growth factor receptor expression in human gastroenteropancreatic neuroendocrine tumors. European J of Clin Invest 1998;28:103849.10.1046/j.1365-2362.1998.00397.x

[71] Berković MC, Mahečić, D.H., Tomašić, V., Hrabar, D., and Zjačić-Rotkvić, V. The Association of Chronic Inflammation and Gastroenteropancreatic Neuroendocrine Tumors (GEP-NETs). Neuroendocrine Tumor 2012.10.5772/34482

[72] Osipo C, Golde TE, Osborne BA, Miele LA. Off the beaten pathway: the complex cross talk between Notch and NF-kappaB. Laboratory investigation; a journal of technical methods and pathology. 2008;88:117.10.1038/labinvest.3700700

[73] Crabtree JS, Singleton CS, Miele L. Notch Signaling in Neuroendocrine Tumors. Frontiers in oncology. 2016;6:94.10.3389/fonc.2016.00094

[74] Briest F, Berg E, Grass I, Freitag H, Kaemmerer D, Lewens F, et al. FOXM1: A novel drug target in gastroenteropancreatic neuroendocrine tumors. Oncotarget. 2015;6:8185-99.10.18632/oncotarget.3600

[75] Harris RE. Cyclooxygenase-2 (cox-2) blockade in the chemoprevention of cancers of the colon, breast, prostate, and lung. Inflammopharmacology. 2009;17:55-67.10.1007/s10787-009-8049-8

[76] Nakajima T, Hamanaka K, Fukuda T, Oyama T, Kashiwabara K, Sano T. Why is cyclooxygenase-2 expressed in neuroendocrine cells of the human alimentary tract? Pathology international. 1997;47:889-91

[77] Cadden I, Johnston BT, Turner G, McCance D, Ardill J, McGinty A. An evaluation of cyclooxygenase-2 as a prognostic biomarker in mid-gut carcinoid tumours. Neuroendocrinology. 2007;86:10411.10.1159/000107555

[78] Ohike N, Morohoshi T. Immunohistochemical analysis of cyclooxygenase (COX)-2 expression in pancreatic endocrine tumors: association with tumor progression and proliferation. Pathology international. 2001;51:770-7.10.1046/j.1440-1827.2001.01273.x

[79] Kim HS, Lee HS, Kim WH. Clinical significance of protein expression of cyclooxygenase-2 and somatostatin receptors in gastroenteropancreatic neuroendocrine tumors. Cancer research and treatment : official journal of Korean Cancer Association. 2011;43:181-8.10.4143/crt.2011.43.3.181 
[80] de Jong PR, Gonzalez-Navajas JM, Jansen NJ. The digestive tract as the origin of systemic inflammation. Critical care. 2016;20:279.10.1186/s13054-016-1458-3

[81] Franceschi C, Garagnani P, Vitale G, Capri M, Salvioli S. Inflammaging and 'Garb-aging'. Trends in endocrinology and metabolism: TEM. 2017;28:199-212.10.1016/j.tem.2016.09.005

[82] Massironi S, Zilli A, Elvevi A, Invernizzi P. The changing face of chronic autoimmune atrophic gastritis: an updated comprehensive perspective. Autoimmunity reviews. 2019;18:215-

22.10.1016/j.autrev.2018.08.011

[83] Campana D, Ravizza D, Ferolla P, Faggiano A, Grimaldi F, Albertelli M, et al. Risk factors of type 1 gastric neuroendocrine neoplasia in patients with chronic atrophic gastritis. A retrospective, multicentre study. Endocrine. 2017;56:633-8.10.1007/s12020-016-1099-y

[84] Murphy G, Dawsey SM, Engels EA, Ricker W, Parsons R, Etemadi A, et al. Cancer Risk After Pernicious Anemia in the US Elderly Population. Clinical gastroenterology and hepatology : the official clinical practice journal of the American Gastroenterological Association. 2015;13:2282-9 e1-4.10.1016/j.cgh.2015.05.040

[85] Vannella L, Sbrozzi-Vanni A, Lahner E, Bordi C, Pilozzi E, Corleto VD, et al. Development of type I gastric carcinoid in patients with chronic atrophic gastritis. Alimentary pharmacology \& therapeutics. 2011;33:1361-9.10.1111/j.1365-2036.2011.04659.x

[86] Kokkola A, Sjoblom SM, Haapiainen R, Sipponen P, Puolakkainen P, Jarvinen H. The risk of gastric carcinoma and carcinoid tumours in patients with pernicious anaemia. A prospective follow-up study. Scandinavian journal of gastroenterology. 1998;33:88-92.10.1080/00365529850166266

[87] Lehtola J, Karttunen T, Krekela I, Niemela S, Rasanen O. Gastric carcinoids with minimal or no macroscopic lesion in patients with pernicious anemia. Hepato-gastroenterology. 1985;32:72-6

[88] Vanoli A, La Rosa S, Luinetti O, Klersy C, Manca R, Alvisi C, et al. Histologic changes in type A chronic atrophic gastritis indicating increased risk of neuroendocrine tumor development: the predictive role of dysplastic and severely hyperplastic enterochromaffin-like cell lesions. Human pathology. 2013;44:182737.10.1016/j.humpath.2013.02.005

[89] Kidd M, Miu K, Tang LH, Perez-Perez GI, Blaser MJ, Sandor A, et al. Helicobacter pylori lipopolysaccharide stimulates histamine release and DNA synthesis in rat enterochromaffin-like cells. Gastroenterology. 1997;113:1110-7.10.1053/gast.1997.v113.pm9322505

[90] Parsons BN, ljaz UZ, D'Amore R, Burkitt MD, Eccles R, Lenzi L, et al. Comparison of the human gastric microbiota in hypochlorhydric states arising as a result of Helicobacter pylori-induced atrophic gastritis, autoimmune atrophic gastritis and proton pump inhibitor use. PLoS pathogens. 2017;13:e1006653.10.1371/journal.ppat.1006653

[91] Judd LM, Gleeson PA, Toh BH, van Driel IR. Autoimmune gastritis results in disruption of gastric epithelial cell development. The American journal of physiology. 1999;277:G20918.10.1152/ajpgi.1999.277.1.G209

[92] Lowenfels AB, Maisonneuve P, Cavallini G, Ammann RW, Lankisch PG, Andersen JR, et al. Pancreatitis and the risk of pancreatic cancer. International Pancreatitis Study Group. The New England journal of medicine. 1993;328:1433-7.10.1056/NEJM199305203282001

[93] Bansal P, Sonnenberg A. Pancreatitis is a risk factor for pancreatic cancer. Gastroenterology. 1995;109:247-51.10.1016/0016-5085(95)90291-0

[94] Capurso G, Falconi M, Panzuto F, Rinzivillo M, Boninsegna L, Bettini R, et al. Risk factors for sporadic pancreatic endocrine tumors: a case-control study of prospectively evaluated patients. The American journal of gastroenterology. 2009;104:3034-41.10.1038/ajg.2009.466

[95] Haugvik SP, Hedenstrom P, Korsaeth E, Valente R, Hayes A, Siuka D, et al. Diabetes, smoking, alcohol use, and family history of cancer as risk factors for pancreatic neuroendocrine tumors: a systematic review and meta-analysis. Neuroendocrinology. 2015;101:133-42.10.1159/000375164

[96] Valente R, Hayes AJ, Haugvik SP, Hedenstrom P, Siuka D, Korsaeth E, et al. Risk and protective factors for the occurrence of sporadic pancreatic endocrine neoplasms. Endocrine-related cancer. 2017;24:40514.10.1530/ERC-17-0040

[97] Swidnicka-Siergiejko AK, Gomez-Chou SB, Cruz-Monserrate Z, Deng D, Liu Y, Huang H, et al. Chronic inflammation initiates multiple forms of K-Ras-independent mouse pancreatic cancer in the absence of TP53. Oncogene. 2017;36:3149-58.10.1038/onc.2016.461 
[98] Solcia E, Vanoli A. Histogenesis and natural history of gut neuroendocrine tumors: present status. Endocrine pathology. 2014;25:165-70.10.1007/s12022-014-9312-0

[99] Di Sabatino A, Giuffrida P, Vanoli A, Luinetti O, Manca R, Biancheri P, et al. Increase in neuroendocrine cells in the duodenal mucosa of patients with refractory celiac disease. The American journal of gastroenterology. 2014;109:258-69.10.1038/ajg.2013.426

[100] Sjolund K, Alumets J, Berg NO, Hakanson R, Sundler F. Duodenal endocrine cells in adult coeliac disease. Gut. 1979;20:547-52.10.1136/gut.20.7.547

[101] Sjolund K, Nobin A. Increased levels of plasma 5-hydroxytryptamine in patients with coeliac disease. Scandinavian journal of gastroenterology. 1985;20:304-8.10.3109/00365528509091655

[102] Ilus T, Kaukinen K, Virta L, Pukkala E, Collin P. Incidence of malignancies in diagnosed celiac patients: a population-based estimate. The American journal of gastroenterology. 2014;109:14717.10.1038/ajg.2014.194

[103] Perez-Cuadrado-Robles E, Lujan-Sanchis M, Elli L, Juanmartinena-Fernandez JF, Garcia-Lledo J, RuanoDiaz $L$, et al. Role of capsule endoscopy in alarm features and non-responsive celiac disease: A European multicenter study. Digestive endoscopy : official journal of the Japan Gastroenterological Endoscopy Society. 2018;30:461-6.10.1111/den.13002

[104] Hallert C, Norrby K. Malignant carcinoid tumour complicating coeliac disease. Acta medica Scandinavica. 1983;213:313-6.10.1111/j.0954-6820.1983.tb03741.x

[105] Gardiner GW, Van Patter T, Murray D. Atypical carcinoid tumor of the small bowel complicating celiac disease. Cancer. 1985;56:2716-22.10.1002/1097-0142(19851201)56:11<2716::aidcncr2820561135>3.0.co;2-I

[106] Kimchi NA, Broide E, Zehavi S, Halevy A, Scapa E. Capsule endoscopy diagnosis of celiac disease and ileal tumors in a patient with melena of obscure origin. The Israel Medical Association journal : IMAJ. 2005;7:412-3

[107] Sottile R, Percopo F, Persico V, Ciacci C. Recidivant midgut neuroendocrine tumor in a celiac patient. The American journal of gastroenterology. 2001;96:608-9.10.1111/j.1572-0241.2001.03575.x

[108] Bojesen RD, Riis LB, Hogdall E, Nielsen OH, Jess T. Inflammatory Bowel Disease and Small Bowel Cancer Risk, Clinical Characteristics, and Histopathology: A Population-Based Study. Clinical gastroenterology and hepatology : the official clinical practice journal of the American Gastroenterological Association. 2017;15:1900-7 e2.10.1016/j.cgh.2017.06.051

[109] Algaba A, Guerra I, Castano A, de la Poza G, Castellano VM, Lopez M, et al. Risk of cancer, with special reference to extra-intestinal malignancies, in patients with inflammatory bowel disease. World journal of gastroenterology. 2013;19:9359-65.10.3748/wjg.v19.i48.9359

[110] Alexandraki KI, Kaltsas GA, Grozinsky-Glasberg S, Chatzellis E, Grossman AB. Appendiceal neuroendocrine neoplasms: diagnosis and management. Endocrine-related cancer. 2016;23:R2741.10.1530/ERC-15-0310

[111] Vasei M, Zakeri Z, Azarpira N, Hosseini SV, Solaymani-Dodaran M. Serotonin content of normal and inflamed appendix: a possible role of serotonin in acute appendicitis. APMIS : acta pathologica, microbiologica, et immunologica Scandinavica. 2008;116:947-52.10.1111/j.1600-0463.2008.00916.x

[112] Szabo GG, Barta Z, Kerekes L, Szakall S. [Association of carcinoid tumor of the appendix and Crohn disease (case report and review of the literature)]. Orvosi hetilap. 1999;140:1635-9

[113] Qiao Y, Yang T, Gan Y, Li W, Wang C, Gong Y, et al. Associations between aspirin use and the risk of cancers: a meta-analysis of observational studies. BMC cancer. 2018;18:288.10.1186/s12885-018-4156-5

[114] Hernandez-Trejo JA, Suarez-Perez D, Gutierrez-Martinez IZ, Fernandez-Vargas OE, Serrano C, Candelario-Martinez AA, et al. The pro-inflammatory cytokines IFNgamma/TNFalpha increase chromogranin A-positive neuroendocrine cells in the colonic epithelium. The Biochemical journal. 2016;473:3805-18.10.1042/BCJ20160390

[115] Laukoetter MG, Nava P, Nusrat A. Role of the intestinal barrier in inflammatory bowel disease. World journal of gastroenterology. 2008;14:401-7.10.3748/wjg.14.401

[116] Fang D, Hawke D, Zheng Y, Xia Y, Meisenhelder J, Nika H, et al. Phosphorylation of beta-catenin by AKT promotes beta-catenin transcriptional activity. The Journal of biological chemistry. 2007;282:112219.10.1074/jbc.M611871200 
[117] Cross DA, Alessi DR, Cohen P, Andjelkovich M, Hemmings BA. Inhibition of glycogen synthase kinase-3 by insulin mediated by protein kinase B. Nature. 1995;378:785-9.10.1038/378785a0

[118] Nava P, Kamekura R, Quiros M, Medina-Contreras O, Hamilton RW, Kolegraff KN, et al. IFNgammainduced suppression of beta-catenin signaling: evidence for roles of Akt and 14.3.3zeta. Molecular biology of the cell. 2014;25:2894-904.10.1091/mbc.E13-09-0512

[119] Shigaki K, Mitomi H, Fujimori T, Ichikawa K, Tomita S, Imura J, et al. Immunohistochemical analysis of chromogranin A and p53 expressions in ulcerative colitis-associated neoplasia: neuroendocrine differentiation as an early event in the colitis-neoplasia sequence. Human pathology. 2013;44:23939.10.1016/j.humpath.2013.06.008

[120] Derikx LA, Vierdag WM, Kievit W, Bosch S, Hoentjen F, Nagtegaal ID. Is the prevalence of colonic neuroendocrine tumors increased in patients with inflammatory bowel disease? International journal of cancer. 2016;139:535-42.10.1002/ijc.30096

[121] West NE, Wise PE, Herline AJ, Muldoon RL, Chopp WV, Schwartz DA. Carcinoid tumors are 15 times more common in patients with Crohn's disease. Inflammatory bowel diseases. 2007;13:112934.10.1002/ibd.20172

[122] Kortbeek J, Kelly JK, Preshaw RM. Carcinoid tumors and inflammatory bowel disease. Journal of surgical oncology. 1992;49:122-6.10.1002/jso.2930490213

[123] Boltin D, Levi Z, Halpern M, Fraser GM. Concurrent small bowel adenocarcinoma and carcinoid tumor in Crohn's disease--case report and literature review. Journal of Crohn's \& colitis. 2011;5:4614.10.1016/j.crohns.2011.04.006

[124] Guadagno E, De Rosa F, Borrelli G, Luglio G, Bucci L, Del Basso De Caro M. High-grade MiNEN in a Long-standing History of Ulcerative Colitis: An Unexpected Evolution. Inflammatory bowel diseases. 2019;25:e38-e9.10.1093/ibd/izy257

[125] Pellino G, Marcellinaro R, Candilio G, De Fatico GS, Guadagno E, Campione S, et al. The experience of a referral centre and literature overview of GIST and carcinoid tumours in inflammatory bowel diseases. International journal of surgery. 2016;28 Suppl 1:S133-41.10.1016/j.ijsu.2015.12.051

[126] Dolan RD, Laird BJA, Horgan PG, McMillan DC. The prognostic value of the systemic inflammatory response in randomised clinical trials in cancer: A systematic review. Critical reviews in oncology/hematology. 2018;132:130-7.10.1016/j.critrevonc.2018.09.016

[127] Liang W, Ferrara N. The Complex Role of Neutrophils in Tumor Angiogenesis and Metastasis. Cancer immunology research. 2016;4:83-91.10.1158/2326-6066.CIR-15-0313

[128] Vikman S, Giandomenico V, Sommaggio R, Oberg K, Essand M, Totterman TH. CD8+ T cells against multiple tumor-associated antigens in peripheral blood of midgut carcinoid patients. Cancer immunology, immunotherapy : Cll. 2008;57:399-409.10.1007/s00262-007-0382-4

[129] Salman T, Kazaz SN, Varol U, Oflazoglu U, Unek IT, Kucukzeybek Y, et al. Prognostic Value of the Pretreatment Neutrophil-to-Lymphocyte Ratio and Platelet-to-Lymphocyte Ratio for Patients with Neuroendocrine Tumors: An Izmir Oncology Group Study. Chemotherapy. 2016;61:2816.10.1159/000445045

[130] Yucel B, Babacan NA, Kacan T, Eren AA, Eren MF, Bahar S, et al. Survival analysis and prognostic factors for neuroendocrine tumors in Turkey. Asian Pacific journal of cancer prevention : APJCP. 2014;14:6687-92.10.7314/APJCP.2013.14.11.6687

[131] Zhou B, Zhan C, Wu J, Liu J, Zhou J, Zheng S. Prognostic Significance of Preoperative Neutrophil-toLymphocyte Ratio in Surgically Resectable Pancreatic Neuroendocrine Tumors. Medical science monitor : international medical journal of experimental and clinical research. 2017;23:557488.10.12659/MSM.907182

[132] Tong Z, Liu L, Zheng $Y$, Jiang $W$, Zhao $P$, Fang $W$, et al. Predictive value of preoperative peripheral blood neutrophil/lymphocyte ratio for lymph node metastasis in patients of resectable pancreatic neuroendocrine tumors: a nomogram-based study. World journal of surgical oncology. 2017;15:108.10.1186/s12957-017-1169-5

[133] Cao LL, Lu J, Lin JX, Zheng CH, Li P, Xie JW, et al. A novel predictive model based on preoperative blood neutrophil-to-lymphocyte ratio for survival prognosis in patients with gastric neuroendocrine neoplasms. Oncotarget. 2016;7:42045-58.10.18632/oncotarget.9805 
[134] Zhou B, Zhan C, Wu J, Liu J, Zhou J, Zheng S. Prognostic significance of preoperative gammaglutamyltransferase to lymphocyte ratio index in nonfunctional pancreatic neuroendocrine tumors after curative resection. Scientific reports. 2017;7:13372.10.1038/s41598-017-13847-6

[135] Wiese D, Kampe K, Waldmann J, Heverhagen AE, Bartsch DK, Fendrich V. C-Reactive Protein as a New Prognostic Factor for Survival in Patients With Pancreatic Neuroendocrine Neoplasia. The Journal of clinical endocrinology and metabolism. 2016;101:937-44.10.1210/jc.2015-3114

[136] Figueroa-Vega N, Diaz A, Adrados M, Alvarez-Escola C, Paniagua A, Aragones J, et al. The association of the angiopoietin/Tie-2 system with the development of metastasis and leukocyte migration in neuroendocrine tumors. Endocrine-related cancer. 2010;17:897-908.10.1677/ERC-10-0020

[137] Srirajaskanthan R, Dancey G, Hackshaw A, Luong T, Caplin ME, Meyer T. Circulating angiopoietin-2 is elevated in patients with neuroendocrine tumours and correlates with disease burden and prognosis. Endocrine-related cancer. 2009;16:967-76.10.1677/ERC-09-0089

[138] Oberg K, Ferone D, Kaltsas G, Knigge UP, Taal B, Plockinger U, et al. ENETS Consensus Guidelines for the Standards of Care in Neuroendocrine Tumors: biotherapy. Neuroendocrinology. 2009;90:20913.10.1159/000183751

[139] Treglia G, Kroiss AS, Piccardo A, Lococo F, Santhanam P, Imperiale A. Role of positron emission tomography in thyroid and neuroendocrine tumors. Minerva endocrinologica. 2018;43:34155.10.23736/S0391-1977.17.02742-0

[140] Fuentes-Fayos AC, Garcia-Martinez A, Herrera-Martinez AD, Jimenez-Vacas JM, Vazquez-Borrego MC, Castano JP, et al. Molecular determinants of the response to medical treatment of growth hormone secreting pituitary neuroendocrine tumors. Minerva endocrinologica. 2019;44:109-28.10.23736/S03911977.19.02970-5

[141] Vitale G, Dicitore A, Sciammarella C, Di Molfetta S, Rubino M, Faggiano A, et al. Pasireotide in the treatment of neuroendocrine tumors: a review of the literature. Endocrine-related cancer. 2018;25:R351R64.10.1530/ERC-18-0010

[142] Mazziotti G, Mosca A, Frara S, Vitale G, Giustina A. Somatostatin analogs in the treatment of neuroendocrine tumors: current and emerging aspects. Expert opinion on pharmacotherapy. 2017;18:1679-89.10.1080/14656566.2017.1391217

[143] Alonso-Gordoa T, Capdevila J, Grande E. GEP-NETs update: Biotherapy for neuroendocrine tumours. European journal of endocrinology. 2015;172:R31-46.10.1530/EJE-14-0354

[144] Ferone D. Italian Society of Endocrinology Career Award Lecture: from somatostatin to...somatomedin. Journal of endocrinological investigation. 2012;35:869-74.10.3275/8583

[145] Vitale G, Lupoli G, Guarrasi R, Colao A, Dicitore A, Gaudenzi G, et al. Interleukin-2 and lanreotide in the treatment of medullary thyroid cancer: in vitro and in vivo studies. The Journal of clinical endocrinology and metabolism. 2013;98:E1567-74.10.1210/jc.2013-1443

[146] Gaida MM, Welsch T, Herpel E, Tschaharganeh DF, Fischer L, Schirmacher P, et al. MHC class II expression in pancreatic tumors: a link to intratumoral inflammation. Virchows Archiv : an international journal of pathology. 2012;460:47-60.10.1007/s00428-011-1175-x

[147] Lamarca A, Nonaka D, Breitwieser W, Ashton G, Barriuso J, McNamara MG, et al. PD-L1 expression and presence of TILs in small intestinal neuroendocrine tumours. Oncotarget. 2018;9:1492238.10.18632/oncotarget.24464

[148] Roberts JA, Gonzalez RS, Das S, Berlin J, Shi C. Expression of PD-1 and PD-L1 in poorly differentiated neuroendocrine carcinomas of the digestive system: a potential target for anti-PD-1/PD-L1 therapy. Human pathology. 2017;70:49-54.10.1016/j.humpath.2017.10.003

[149] Cavalcanti E, Armentano R, Valentini AM, Chieppa M, Caruso ML. Role of PD-L1 expression as a biomarker for GEP neuroendocrine neoplasm grading. Cell death \& disease. 2017;8:e3004.10.1038/cddis.2017.401

[150] Kim ST, Ha SY, Lee S, Ahn S, Lee J, Park SH, et al. The Impact of PD-L1 Expression in Patients with Metastatic GEP-NETs. Journal of Cancer. 2016;7:484-9.10.7150/jca.13711

[151] Bosch F, Bruwer K, Altendorf-Hofmann A, Auernhammer CJ, Spitzweg C, Westphalen CB, et al. Immune checkpoint markers in gastroenteropancreatic neuroendocrine neoplasia. Endocrine-related cancer. 2019;26:293-301.10.1530/ERC-18-0494 
[152] Sampedro-Nunez M, Serrano-Somavilla A, Adrados M, Cameselle-Teijeiro JM, Blanco-Carrera C, Cabezas-Agricola JM, et al. Analysis of expression of the PD-1/PD-L1 immune checkpoint system and its prognostic impact in gastroenteropancreatic neuroendocrine tumors. Scientific reports. 2018;8:17812.10.1038/s41598-018-36129-1

[153] Pinato DJ, Brown M, White SDT, Zhang H, Toloue S, Dina R, et al. Programmed cell death (PD-1) ligands expression in gastro-entero-pancreatic neuroendocrine tumours (GEP-NETs): relationship with angiogenesis and clinical outcome. Journal of Clinical Oncology. 2016;34:e15658e.10.1200/Jco.2016.34.15_Suppl.E15658

[154] Cives M, Strosberg J, Al Diffalha S, Coppola D. Analysis of the immune landscape of small bowel neuroendocrine tumors. Endocrine-related cancer. 2019;26:119-30.10.1530/ERC-18-0189

[155] Mehnert J.M. RHS, O'Neil B.H., Santoro A., Schellens J.H.M.,Cohen R.B., Doi T., Ott P.A., Pishvaian M.J.,Puzanov I., Aung K.L., Hsu C., Le Tourneau C., Soria J.C.,.Élez E., Tamura K., Gould M., Zaho G., Stein K., PihaPaul S.A. Pembrolizumab for patients with PD-L1-positive advanced carcinoids or pancreatic neuroendocrine tumors: results from the KEYNOTE-028 study. Annals of Oncology. 2017;28:v142v57.10.1093/annonc/mdx368 